\title{
Implicit Social Cognition
}

\author{
Brian A. Nosek \\ Carlee Beth Hawkins \\ Rebecca S. Frazier
}

University of Virginia

Acknowledgements: This project was supported by Project Implicit, Inc. Nosek is an officer and Hawkins is a consultant of Project Implicit, a non-profit organization that includes in its mission "To develop and deliver methods for investigating and applying phenomena of implicit social cognition, including especially phenomena of implicit bias based on age, race, gender or other factors." 
Some of the most influential examples of scientific genius start with a powerful idea followed by development of methods to evaluate it. Einstein's theories of relativity were a remarkable insight that inspired decades of methodological innovation to confirm it. Most scientists, however, are no Einstein. Scientific progress can also accelerate rapidly in the reverse direction. Methods may generate evidence that inspires new ideas and theories. This is evident, for example, in Nobel Prize winner citations over a 13-year span for Physics, Chemistry, and Physiology and Medicine. Eighty-four percent of the citations credited a methodological achievement as the primary basis for the prize as opposed to a theoretical advance (Greenwald, 2001). In empirical research, theory and method are interdependent. Theoretical advances may spur methodological innovation by identifying a new possibility that has not yet been investigated. Methodological advances may spur theoretical innovation by producing evidence that existing theories are not prepared to explain, and by providing new avenues for empirical study. The rapid growth of knowledge in implicit social cognition over the last two decades can credit methodological more than theoretical innovation.

The theoretical foundation of implicit social cognition has a long history. Helmholtz (1910/1925) suggested that many mental processes occurred outside conscious awareness. Freud (1900) brought ideas about the unconscious into the public sphere, kindling the imagination and adding trepidation about offering a banana to one's mother. While Freud's methods have gone the way of the Cro-Magnon, the idea that mental processes can escape introspective access and influence behavior is an ancestor of the modern field of implicit social cognition. This field started to congeal following the emergent understanding that people do not observe their mental processes (Nisbett \& Wilson, 1977). People can be mistaken, perhaps quite easily, about why they do the things they do. Following that, measurement innovation in cognitive psychology 
initiated investigation of memory without requiring that the respondent be able to report the memory (see Roediger, 1990 for a review). These methods and ideas were then applied to social cognition (Greenwald \& Banaji, 1995).

The invention of two methods, in particular - sequential evaluative priming (EP; Fazio et al., 1986; Fazio et al., 1995) and the Implicit Association Test (IAT; Greenwald, McGhee, \& Schwartz, 1998) - launched a surge of research. These methods and their kin have stimulated growth in theory and evidence about thoughts and feelings that occur outside of conscious awareness or conscious control and how they impact social perception, judgment and action. In this chapter, we attempt to synthesize the last 15 years of research in implicit social cognition in 16,000 words or less. More words are available in the marvelous 29-chapter Handbook of Implicit Social Cognition (Gawronski \& Payne, 2010).

\section{Definition: What Is Implicit? How Do We Decide?}

A disquieting answer to the question "What is implicit?" is that there is no correct answer. Definitions of concepts are created in the service of theory and interpretation of evidence. Psychological constructs are unobservable - not because we do not know where to look, but because they are not physical objects. As such, the definitions that describe those constructs are arbitrary. Their correctness is a function of how useful they are in connecting theory with evidence. Construct definitions and theory are refined to better reflect observed measurement, and measurement is improved to assess constructs as they are represented in definition and theory. This illustrates the fundamental interdependence of theory and measurement (e.g., Ostrom, 1991).

As a consequence, a question like - Are implicit social cognitions unconscious? - is not an interesting question. The answer could be definitively yes or definitively no without 
conducting any research. If the definition is fixed in advance, the only empirical question would be whether a measure can be invented to assess implicit social cognition. If no measure can be found, then either implicit social cognition does not exist, or scientists are not creative enough to measure it. In this scenario, the researcher has two options - invent more measurement methods to assess implicit social cognition, or change the construct definition toward what the available measurement methods measure. The first is theory driven and might be preferred when there is a strong theoretical expectation (e.g., the intensive methodological innovation to find evidence for Einstein's theories of relativity). The second is measurement driven and might be preferred when something interesting has been observed and is not yet understood (e.g., the years of intensive theoretical innovation to explain the insufficient justification effect; Bem, 1967; Festinger, 1957; Greenwald \& Ronis, 1978; Jones, Mills, et al., 1999). In implicit social cognition research, the invention of implicit measures occurred because self-reported social cognitions were not as successful predicting some behaviors that they theoretically should be predicting (e.g., differential behavior with Black or White targets that is unrelated to self-reported racial attitudes). Following their invention, it became clear that implicit measures revealed effects that went well beyond existing theoretical predictions. As such, implicit social cognition is an example of the interactive feedback between theory and measurement - an initial theoretical insight spurred methodological advances that have, in turn, stimulated theoretical innovation to explain the new findings.

Greenwald and Banaji (1995) introduced the term implicit social cognition for describing thoughts and feelings that occur outside of conscious awareness or conscious control in relation to social psychological constructs - attitudes, stereotypes, and self-concepts. Greenwald and Banaji defined implicit constructs this way: "An implicit [construct] is the introspectively 
unidentified (or inaccurately identified) traces of past experience that mediates [the relevant category of responses]" (1995, p. 5). For example, the relevant category of responses for the construct attitudes might be evaluations of social concepts.

The definition's phrase, "traces of past experience" suggests that the content need not be accessible to awareness, believed by possessor as true or false, or used with intention to have it influence social judgment. People may intend a course of action explicitly, but still do something different because of cognitions operating implicitly. Also, the definition uses "unidentified" to refer to the measured content. This is importantly different from "unidentifiable." "Unidentified" does not require that people cannot, across time, place, or situation, ever identify the relevant traces of past experience, just that they are not identified in that circumstance. In fact, the additional clause "inaccurately identified" denotes that the person may have some experience of the relevant content, but not report it accurately because they do not want others to know it, they do not believe it themselves, or they do not know how to translate the mental content into a report (Nosek \& Greenwald, 2009).

This definition of "implicit" is descriptive. It is agnostic to the particular cognitive processes that might be influential in implicit social cognition. This has important consequences. As a descriptive term, "implicit" is not committed to any particular theoretical interpretation of the mechanisms underlying implicit social cognition. The term is inclusive of a heterogeneous family of processes. Many theoretical positions can (and have) emerged to explain implicit social cognition with distinct mechanisms. A common theme is a dual-process orientation in which the implicit-explicit distinction is understood to reflect different systems or processes such as automatic-controlled, spontaneous-deliberate, associative-rule-based, heuristic-systematic, unconscious-conscious, efficient-effortful, unintentional-intentional, and impulsive-reflexive 
(Chaiken \& Trope, 1999; Smith \& DeCoster, 2000). By adopting a descriptive definition, the understanding of "what is implicit?" will change as evidence accumulates.

With a diversity of measurement methods and a growing understanding of how they function, there is an emerging foundation for evaluating and refining the taxonomy of implicit social cognition. "Implicit" may be an umbrella concept for component processes that have unique influences on thinking and behavior leading to a richer network of constructs and theory that will provide specific predictions about resulting behavior (Moors \& De Houwer, 2009). And, if the taxonomy that emerges leaves out important ideas of what could be influential in implicit processes, it may cycle back and spur a new round of methodological innovation to measure those cognitions.

\section{Measurement}

The signature feature of implicit measures is that their assessment of social cognition is indirect. With an explicit measure, the response directly reflects the content. Answering "Yes" or "No" to the question "Do you like Hillary Clinton?" is a direct assessment of liking of Hillary Clinton. Those responses to the same question could also be indirect assessments of attitudes toward female leaders, women, or Americans. There is a long history of designing self-report measures for which the content of interest may not be apparent to the respondent. The Modern Racism Scale (McConaughy \& Betts, 1986), for example, was designed to assess racial attitudes indirectly by asking people about policy positions that have racial implications. The directly measured contents are the policy positions, and the indirect content of interest is racial attitude that may influence these policy positions.

These examples illustrate two challenges for implicit measurement. For one, extraneous variation is more likely with indirect than direct measurement. Individual differences in attitudes 
toward Hillary Clinton, the individual, could add unwanted variation for measuring attitudes toward female leaders, women, or Americans (not to mention that this measure would provide identical estimates of all three of these attitudes). Likewise, attitudes toward the policy position items of the Modern Racism Scale may be influenced by factors distinct from racial attitudes, such as conservatism (e.g., Fazio, et al., 1995; Weigel \& Howes 1985). To the extent that the directly measured content has meaningful variation independent of the indirect construct-ofinterest, validity of the measure will be reduced.

The second challenge is that indirectness of measurement is not always guaranteed. For example, if respondents understand the Modern Racism Scale to be assessing racial attitudes, then the direct response may - in fact - be their racial attitude, not their policy preferences. Recognizing the measure as a direct assessment of racial attitudes gives respondents awareness, intention and control over their responses. Nonetheless, a variety of measures productively use self-reports to make inferences about implicit social cognition (Karpinski, Steinberg, Versek, \& Alloy, 2007; Maass, Salvi, Arcuri, \& Semin, 1989; Nuttin, 1985; Sekaquaptewa, Espinoza, Thompson, Vargas, \& von Hippel, 2003) by examining responses in ways that respondents are quite unlikely to anticipate and control.

Other methods, such as EP (Fazio et al., 1986) provide more confidence about the indirectness of measurement because of their procedural features. In EP, target words such as "wonderful" or "terrible" appear one-at-a-time on a computer screen and participants rate them as pleasant or unpleasant as quickly as they can. Right before the target word is presented, a prime - such as a face, word, or image - appears briefly. If the prime is negative it may facilitate (speed up) ratings of negative target words and disrupt (slow down) ratings of positive target words. In this case, the direct response is the response latency of rating the target word - the 
response itself has nothing to do with the prime. The indirect assessment of evaluation is inferred by a comparison of behavioral responses: the average response latency of categorizing pleasant words after flashing a positive prime, and the average response latency of categorizing the same positive words after flashing a negative prime.

These methods increase the likelihood that assessment is indirect, but still do not guarantee it. For example, using the Affect Misattribution Procedure (AMP, Payne, Cheng, Govorun, \& Stewart, 2005), a similar procedure to EP, Bar-Anan and Nosek (2011) found that, despite instructions to ignore the primes, some participants reported rating primes instead of targets. Without those participants the AMP's internal consistency and relations with criterion measures were much weaker. Likewise, the "personalized" procedural changes to the "original" IAT format (Olson \& Fazio, 2004) appear to promote more direct evaluation of target concepts among some participants, and this may account for the former's stronger correlation with selfreported attitudes (Nosek \& Hansen, 2008a).

The common theme in these examples is that participants may not perform implicit tasks as instructed because they misunderstand what they are supposed to do, or otherwise fail to do it. With explicit measurement, participant misunderstanding or misbehavior usually damages the possibility for the measure to relate to anything of interest. This is possible with indirect measurement too. Responding randomly in EP, the AMP or the IAT will reduce its correlation with covariates. However, as in the above examples, if the failure to follow instructions turns an indirect measure into a direct measure, then the resulting effects could appear to be sensible and even increase relations with criterion variables. The problem is that the effects might be misunderstood to indicate implicit social cognition when it is actually explicit. 
To summarize, the virtues of implicit measures are that they do not depend on the respondent's willingness and ability to report the content of interest. As long as respondents follow task instructions, indirect content may influence responses without awareness, intention, or control. Implicit measures get, and deserve, more scrutiny than explicit measures because they often lack the face validity of direct measures: the content-of-interest is not clearly indicated by the responses. And, because of their indirectness, implicit measures often have weaker internal consistency and are influenced by more extraneous factors. These have implications for the power and validity of implicit measurement.

\section{Implicit Measurement Procedures}

There are a variety of measurement methods for implicit social cognition. Many are flexible procedures that can be adapted to assess a variety of social constructs (e.g., attitudes, identities, stereotypes, beliefs, self-esteem). Nosek, Hawkins, and Frazier (2011) conducted a citation analysis of 20 articles that introduced an implicit measurement procedure to estimate each measure's impact and use. They found that: (a) the IAT accounted for more than $40 \%$ of the total citations and about $50 \%$ of citations in the most recent year (2010), (b) EP was the second most cited with $20 \%$ of total citations and about $12 \%$ of citations in 2010 , (c) a cluster of the AMP, Go/No-go Association Task (GNAT; Nosek \& Banaji, 2001), Single-Target Implicit Association Test (STIAT; Karpinski \& Steinman, 2006), Lexical Decision Task (LDT; Wittenbrink, Judd, \& Park, 1997), and Extrinsic Affective Simon Task (EAST; De Houwer, 2003) each had between 4-6\% of the citations, and (d) a recent burst of new methods suggests continuing growth and innovation in implicit measurement.

The IAT and EP have been extensively reviewed elsewhere (Fazio \& Olson, 2003; Lane, Banaji, Nosek, \& Greenwald, 2007; Nosek, Greenwald, \& Banaji, 2007; Teige-Mociemba, 
Klauer, \& Sherman, 2010; Wentura \& Degner, 2010). We review them here briefly in the context of a broader view of implicit measures. Several criteria have been put forward for determining what makes a measure implicit (De Houwer, Teige-Mocigemba, Spruyt, \& Moors, 2009; De Houwer \& Moors, 2010). Here, we organize implicit measures into four categories: indirect self-report tasks, priming tasks, categorization tasks, and approach-avoid tasks.

Indirect self-report. The Linguistic Intergroup Bias (LIB; Maass, et al., 1985) uses selfreported explanations of others' behavior to measure implicit cognition. The linguistic category model (Semin \& Fiedler, 1988) outlines categories for describing human behavior that range from concrete (e.g., single behaviors such as to touch) to abstract (e.g., dispositions such as aggressive). In the LIB, participants describe the actions of cartoons showing ingroup or outgroup members. Positive actions performed by ingroup members are described abstractly, whereas the same action performed by outgroup members are described more concretely (e.g., Maass, et al., 1985). The linguistic descriptions suggests that identical positive behavior is credited as indicating good character for ingroup members, but not for outgroup members. Other indirect self-report measures draw on similar linguistic principles, such as the Stereotype Explanatory Bias (SEB; Sekaquaptewa, et al., 2003) for measuring implicit stereotyping, and the Breadth-based Adjective Rating Task (BART; Karpinski, et al., 2007) for measuring implicit self esteem.

The Name Letter Effect (NLE; Nuttin, 1985) also uses self-report for measuring implicit self-evaluation. Participants evaluate how much they like the letters of the alphabet. People reliably prefer letters in their own name compared to other letters (Nuttin, 1985), and the numbers of their birthday compared to other numbers (Koole, Dijksterhuis, \& van Knippenberg, 2001). Variation in the strength of liking letters or numbers associated with the self is related to 
outcome variables such as parenting style (DeHart, Pelham, \& Tennen, 2006) and future depressive symptoms (Franck, De Raedt, \& De Houwer, 2007). An obvious concern is that, for some participants, evaluating letters in their name more positively could generate a direct, intentional evaluation of the self thereby undermining the measure's implicitness (" $\mathrm{H}$ is for Haven. That's me!").

Priming tasks. Priming tasks were the first widely-used individual difference measures of implicit cognition (Fazio et al., 1986; Wentura \& Degner, 2010). Evaluative priming (EP) established that evaluations can be activated automatically upon encountering a social object (Fazio et al., 1986). This automatic evaluation may occur universally (Bargh et al., 1992), even for objects that the person has never experienced previously (Duckworth, Bargh, Garcia, \& Chaiken, 2002). EP is most commonly used to measure attitudes, but the paradigm has been extended to measure automatic goals (Ferguson, 2007), ingroup liking in the minimal group paradigm (Otten \& Wentura, 1999), self-concept (Hetts, Sakuma, \& Pelham, 1999), and selfesteem (Spalding \& Hardin, 1999).

LDT is procedurally similar to $\mathrm{EP}$ - a prime is presented (e.g., BLACK or WHITE) quickly followed by a judgment of whether a target stimulus is a word or not. As in EP, the lexical decision is facilitated by the prime. For example, WHITE primes accelerate identifying words that are stereotypically associated with White people and BLACK primes facilitate identifying words that are stereotypically associated with Black people. The AMP is procedurally similar to EP and LDT - a prime is presented followed quickly by a Chinese pictograph. The pictograph is presented only briefly, and participants' task is to evaluate the pictograph as unpleasant (less pleasant than the average pictograph) or pleasant (more pleasant 
than the average pictograph). Unlike EP and LDT, AMP scores are calculated based on the proportion of pleasant ratings, not average response times.

These procedures are similar, but their unique features may be important for how they function. LDT and EP are the same except for the response decision - "is it a word?" versus "is the word good or bad?" Facilitation of these decisions by the primes may be a function of distinct processes (De Houwer, 2003). And, because the AMP targets are designed to be evaluatively neutral, the pleasantness decision in the AMP is not a function of the evaluative match or mismatch between prime and target, as it is in EP and LDT. Rather, it is a result of misattributing affect elicited by the prime to the neutral target (Payne et al., 2005).

An important feature shared by EP, LDT, and possibly the AMP is that their effects are more influenced by the items than the categories (Olson \& Fazio, 2003). Unique features of the individual primes can elicit very different effects, even if they are drawn from the same social category (Livingston \& Brewer, 2002). In most applications of these tasks, respondents are told to ignore, remember, or do nothing with the primes, but rarely are they instructed to identify the social categories the primes exemplify. As such, priming effects tend to be more sensitive to characteristics of individual stimulus items unless a category is made accessible. When the category of the primes is made accessible, the reliability of the effect increases as does its relation with category-driven implicit measures (Olson \& Fazio, 2003).

Categorization tasks. Whereas priming tasks assess the respondent's spontaneous reactions to primes, categorization tasks define the feature or features for how stimulus items should be processed. For example, presenting Barack Obama as a prime in EP might activate evaluations of Barack Obama, men, black people, or U.S. presidents (among other things) and those activations might influence responses to the subsequent target. In a categorization task, 
Barack Obama might be presented as a stimulus, but the task would define whether he should be categorized as his individual identity, or as an example of men, black people, or U.S. presidents. As a consequence, categorization tasks tend to be more sensitive to the defined categories compared to priming tasks, unless there are alternative categories that are accessible and can be applied to all stimuli (Govan \& Williams, 2004; Mitchell, Nosek, \& Banaji, 2003; Nosek, Greenwald, \& Banaji, 2005).

The IAT is a categorization task. Participants categorize stimuli into concept categories (e.g., Democrats and Republicans) and attribute categories (e.g., self and other). One concept category and one attribute category share a response key (e.g., Democrat and self are categorized with the 'e' key) and the other concept and attribute category share a separate response key (e.g., Republican and other are categorized with the ' $\mathrm{i}$ ' key). Then, the concept categories are switched - Democrat and other share a response key and Republican and self share a response key (Greenwald, et al., 1998). The difference in average response latency to categorize the items between those response conditions is taken to indicate the relative strength of association between concepts and attributes. Most Democrats are faster at categorizing the items when Democrat and self share a response key compared to Republican and self; whereas Republicans are the opposite (Lindner \& Nosek, 2009).

The IAT is the most popular implicit measure partly because this procedure is easily adapted to measure a variety of mental contents by changing the categories and stimuli representing them. Also, compared to other implicit measures, its internal consistency and testretest reliability are strong, which makes it easier to observe relations with other variables (Nosek et al., 2007). Nonetheless, like all measures, its procedural format puts constraints on its applicability, and it is vulnerable to extraneous influences. The IAT reveals relative association 
strengths among four categories (Nosek et al., 2005). Some alternate measures have been created that measure associations without defining a contrast category - for example, the GNAT, Brief IAT, and STIAT. Novel procedural formats have been introduced recently to eliminate potential differences in response strategies between blocks, such as the Single Block Implicit Association Test (SB-IAT; Teige-Mocigemba, Klauer, \& Rothermund, 2008), the Recoding Free Implicit Association Test (IAT-RF; Rothermund, Teige-Mocigemba, Gast, \& Wentura, 2009), and the Sorting Paired Feature task (SPF; Bar-Anan, Nosek, \& Vianello, 2009). Very little is known about their psychometric properties in comparison to established measures.

Several mechanisms have been proposed to explain IAT effects (Teige-Mocigemba, et al., 2010). A multinomial model called the QUAD model proposes that four processes contribute to IAT effects: automatic activation of associations, the ability to determine a correct response, success of overcoming the activated associations, and guessing (Conrey, Sherman, Gawronski, Hugenberg, \& Groom, 2005). Such models explicitly represent the fact that no measure is process-pure. Identification and parsing of operative processes can improve understanding of the measurements operation itself, and anticipate relations among implicit measures that will each employ a unique constellation of processes.

Approach-avoid tasks. Approach-avoid tasks incorporate movement toward or away from presented stimuli to detect whether concepts automatically elicit approach or avoidance tendencies. For example, the Implicit Association Procedure (IAP; Schnabel, Banse, \& Asendorpf, 2006) is the IAT but instead of pressing response keys to categorize stimuli to the left or right, participants pull a joystick toward the self (approach) or push it away from the self (avoid; Schnabel, et al., 2006). In a shyness IAP, shy and me would be mapped to the pull response and non-shy and not-me would be mapped to the push response, then the two concepts 
(shy and non-shy) are reversed. Self-associations with shyness are reflected by faster approach responses when shy is mapped to pulling the joystick toward oneself than when it is mapped to the pushing away response (avoid), suggesting that associations can be measured with physical actions of pushing and pulling in relation to the self. Similarly, in the Stimulus Response Compatibility Task (SRCT; Mogg, Bradley, Field, \& De Houwer, 2003) participants use arrow keys to move an image of a person toward or away from a stimulus, such as a cigarette (see also Brendl et al., 2005).

These tasks reveal embodied implicit responses to objects in the environment and have been applied primarily to domains in which approach-avoidance tendencies have implications for social functioning, such as tendencies to approach or avoid (a) drugs and alcohol (e.g., Mogg, et al., 2003), (b) crowds among socially anxious individuals (Lange, et al., 2010), and (c) spiders among children with spider fear (Klein, Becker, \& Rinck, 2010).

\section{Next Steps for Implicit Measurement}

Despite there being a healthy diversity of measures available, current uses of implicit measures suggest that the research is dominated by the IAT and, to a lesser degree, EP (Nosek et al., 2011). Measurement procedures exist in the service of identifying psychological constructs. Only in rare cases is it worthwhile to treat a single procedure as the only means of assessing a construct. As such, attention to the refinement of existing measurement practices and invention of new techniques will facilitate construct validation that is not constrained to the idiosyncratic features of specific measurement tools.

\section{Structure: Construct Validity of Implicit Social Cognitions}

Construct validation is a cumulative process of gathering evidence to form a "nomological network" for conceptual and empirical justification of a construct (Cronbach \& 
Meehl, 1955). Psychological constructs are not physical things; they are abstractions that transform a continuous, distributed, cacophony of mental activity into tractable units. Constructs are the building blocks of theories that explain how those constructs operate and interact to produce human behavior. Despite their arbitrariness, some construct taxonomies are more effective than others by using as few constructs as are needed, accounting for as much variation as possible, and providing means for the resulting theories to be generative, testable, and comprehendible. Research in implicit social cognition suggests that the taxonomy of social cognitions - attitudes, stereotypes, beliefs, self-concepts - is usefully divided into two components, explicit and implicit.

\section{Convergent and Divergent Validity}

Validating distinct implicit and explicit social cognitions requires evidence for divergent validity - that measures of the constructs are not assessing the same thing, and simultaneously requires evidence for convergent validity - that the implicit and explicit measures are reasonably interpreted as assessing the same type of thing (Greenwald \& Nosek, 2009). Such evidence comes in multiple forms, such as demonstrations that both implicit and explicit measures predict expected group differences, that implicit and explicit effects follow predictions from theories of social cognition, and that implicit and explicit measures have related and distinct components.

Known-group differences. A straightforward approach for construct validation is to identify groups for which there is a strong theoretical or pre-existing empirical basis to expect them to differ on a social cognition and then demonstrate this difference. For example, implicit measures have been used to distinguish omnivores from vegetarians (Swanson, Rudman, \& Greenwald, 2001), socially anxious from non-anxious controls (Lange, Keijsers, Becker \& Rinck, 2008), gay people from straight people (Snowden, Wichter, \& Gray, 2007), and people 
with snake fears versus spider fears (Teachman, Gregg, \& Woody, 2001). In some cases, these group differences show convergent validity with self-report, and in others, implicit measures were more sensitive to detecting the group difference than was self-report. Demonstrating the latter, convicted pedophiles are very reluctant to self-report attraction to children, but an IAT measuring associations of sex with adults or children distinguished pedophiles from other violent offenders who had not committed sexual crimes against children (Gray, Brown, MacCulloch, Smith, and Snowden, 2005; also Brown, Gray, \& Snowden, 2009).

Theory testing. The prior section advances the evidence for convergent validity that implicit and explicit measures show expected known-groups, and divergent validity with implicit measures predicting group differences that are not effectively predicted by self-report. Divergent validity can also be demonstrated when implicit measures do not show a group difference that is observed explicitly and follows theoretical expectations (i.e., is not just a failure to observe a difference that should have been detected).

One example comes from system justification theory. Preference for one's ingroups compared to outgroups is a pervasive human characteristic (Tajfel \& Turner, 1986). In-group preference emerges implicitly as well, with minimal-group inductions in which the mere assignment to a group leads to a preference for it (Ashburn-Nardo, Voils, \& Monteith, 2001). However, system justification theory offers a hypothesis about conditions under which ingroup favoritism may not be observed, particularly implicitly (Jost, Banaji, \& Nosek, 2004). System justification theory suggests that people are motivated to view the existing system as just, including status and hierarchy differences. As a consequence, members of lower status groups may show weak or no ingroup favoritism to justify their lower status. This pattern is often not observed in self-reported attitudes about one's own group. However, implicitly, members of 
lower status groups tend to show weaker implicit ingroup preference than members of higher status groups show for theirs, including San Jose State students compared to neighboring Stanford (Jost, Pelham, \& Carvallo, 2002), Black people compared to White people (Nosek et al., 2007), and gay people compared to straight people (Jost et al., 2004).

Another example of theory testing demonstrating construct validity comes from balanced identity theory, which anticipates relations among attitudes, stereotypes, and self-concepts following cognitive consistency principles (Greenwald et al., 2002). Among gender identity, academic gender stereotypes, and academic identity, for example, one construct should be predicted by the product of the other two. Women who identify with female and associate female with math should likewise associate self with math to maintain cognitive consistency (Nosek, Banaji, \& Greenwald, 2002). Greenwald et al. (2002) found that balanced identity patterns are more consistently observed implicitly than explicitly. Theory testing provides useful support for construct validation, particularly when such evidence is not anticipated or observed with explicit measures.

Implicit-explicit relations. Early construct validity evidence emphasized divergent validity by showing the lack of relationship between implicit and explicit measures of the same concepts (Fazio et al., 1995; Greenwald \& Banaji, 1995; Greenwald et al., 1998). As the nomological net for explicit social cognition was already well-developed, this led some to wonder if implicit measures were valid assessments of social cognition at all (Arkes \& Tetlock, 2004; Karpinski \& Hilton, 2001; see Banaji, 2001, for a counter view). A good deal of evidence for convergent validity has since accumulated showing that implicit and explicit social cognitions are distinct, but related (Cunningham, Preacher, \& Banaji, 2001; Hofmann, 
Gschwendner, Nosek \& Schmitt, 2005; Hofmann, Gawronski, Gschwendner, Le, \& Schmitt, 2005; Nosek, 2005, 2007; Nosek \& Hansen, 2008b; Nosek \& Smyth, 2007).

The early evidence tilted strongly toward dissociation of implicit and explicit social cognition for at least two reasons. First, the investigations did not account for the very low internal consistency of some implicit measures. When latent modeling is used to remove random error, relations between implicit and explicit measures are substantially strengthened (Cunningham et al., 2001; Nosek, 2007). Second, evidence of implicit-explicit dissociation was most apparent because the initial applications of implicit measures were those domains in which dissociation with self-report was anticipated. Many people are reluctant to report anything other than equal evaluations of Blacks and Whites, but nonetheless may possess social cognitions about race that predict behavior. Fazio and colleagues (Fazio et al., 1995; see also Dovidio et al., 2002; McConnell \& Leibold, 2001) showed that EP detected variability in racial evaluations that was not related to self-report and this variation predicted differential behavior with Black and White targets. As the application of implicit measurement diversified to domains that did not have significant self-presentational demands, stronger implicit-explicit relations were observed. Large studies across 57 (Nosek, 2005) and 98 topics (Nosek \& Hansen, 2008b) showed that implicit-explicit correlations range from near zero (e.g., Future vs. Past, r=.14; Forgiveness vs. Punishment, $r=.16$ ) to strongly positive (e.g., pro-choice vs. pro-life, $r=.62$; cats vs. dogs, $r=.59$ ), with an average correlation across topics of .36 for both studies, that increased to .48 after accounting for measurement error (Nosek \& Smyth, 2007). Notably, there are no known, replicable instances of implicit and explicit measures of the same construct having a reliable negative correlation. Implicit and explicit social cognitions are positively related to varying degrees. 


\section{Moderators of the Relationship between Implicit and Explicit Social Cognition}

The positive relationship between implicit and explicit social cognition supports convergent validity. What accounts for the variation in implicit-explicit relations? Divergent validity would not be supported if that variability was attributable to extraneous factors, such as individual difference tendencies to select extreme answers on self-report measures or individual differences in average response time for categorizing stimuli in implicit measures that use response latency as a dependent variable. To demonstrate divergent validity, the evidence must show that the explanation of the difference between measures has something to do with the construct, not just extraneous procedural factors.

Extraneous influences. All measurement is imperfect. Some error is random-- reducing the reliability, power, and sensitivity to experimental manipulations. Other error is systematic and results from features of the measurement procedure or influences that are immaterial to the construct. For example, in EP, priming effects can be eliminated or reversed when participants are directed to prepare for opposite-valence targets following the primes, suggesting that automatic evaluation isn't the only influence on EP effects (Klauer \& Teige-Mociemba, 2007). In tasks like the IAT and GNAT, participants can deliberately slow down their responding in one condition to alter their score, though this strategy may be partly detectable and correctable (Cvencek et al., 2010). The bulk of evidence on faking suggests that participants need some experience with a measure first, and it may not occur spontaneously very frequently (Fiedler \& Bluemke, 2005; Kim, 2003; Steffens, 2004). Nonetheless, the cautious conclusion is to presume that no implicit measure is impervious to manipulation and that detection methods and measurement innovation should be pursued to identify and minimize their impact. 
Most research on extraneous influences focuses on implicit measures that contrast performance conditions and use response latency as a dependent variable. With the IAT, for example, the performance condition performed first (e.g., categorize Democrats with self and Republicans with other) can increase the difficulty of completing the condition performed second (i.e., Democrats with other, and Republicans with self). Ideally, the discovery of extraneous factors leads to measurement innovation to reduce their influence. In this case, a simple procedural change in practice trials can reduce this extraneous influence (Nosek, Greenwald, \& Banaji, 2005). Another well-known extraneous factor is average response latency. In any paradigm comparing performance across conditions using speeded response time as a dependent variable, people who perform the task faster on average will tend to show smaller mean latency differences between conditions than people who perform the task slower on average (Blanton et al., 2006; Sriram, Nosek, \& Greenwald, 2009). This is a function of response latency distributions and is an interpretation threat for difference scores. A scoring procedure, called the $D$-algorithm (Greenwald, Nosek, \& Banaji, 2003), reduces this influence by scaling the difference between conditions by the overall variability in response times, creating an individual effect size (Cai, Sriram, Greenwald, \& McFarland, 2004; Nosek \& Sriram, 2007). A related influence, average differences in task switching ability are likewise reduced by the $D$ algorithm (Mierke \& Klauer, 2003).

Do extraneous factors like these account for variation in implicit-explicit relations? At a minimum, extraneous influences will reduce implicit-explicit relations overall (unless the same extraneous factor affects implicit and explicit measures). For example, Payne (2008) demonstrated that minimizing the structural differences in implicit and explicit measurement methods increased the correlation between the measures. It is likely that the reduction of 
extraneous differences contributed to this result. Nosek and Smyth (2007) conducted a multitrait-multimethod (Campbell \& Stanley, 1959) investigation with seven topics and found that the distinction between IAT and self-reported attitude measures was not accounted for by systematic methodological influences. However, strong validation requires determining what does account for differences between implicit and explicit measures, as opposed to just showing that extraneous influences do not account for variation in that relationship.

Person versus culture. Implicit social cognitions are presumed to reflect experience with a social concept whether or not the individual believes the information to be true (Banaji et al., 2004; Gawronki \& Bodenhausen, 2006; Nosek \& Hansen, 2008b). Explicit social cognitions, on the other hand, are endorsed by the virtue of the individual reporting them as his or her thoughts or feelings. As such, identifying experiences that the individual might have but not endorse could help clarify the divergence between implicit and explicit social cognition.

One manifestation of this potential moderator of implicit-explicit relations is cultural knowledge - what a person perceives to be culturally valued or believed. For example, one could personally have a strong preference for gay people compared to straight people, but simultaneously perceive that the culture has a strong preference in the opposing direction. Explicit assessments would primarily reflect the former, and implicit assessments might be influenced by both. Two perspectives anticipate this, but have different interpretations of its implications. From one perspective, cultural knowledge would be an extraneous influence, getting in the way of measuring "personal" thoughts and feelings (Arkes \& Tetlock, 2004; Karpinski \& Hilton, 2001; Olson \& Fazio, 2004). From another perspective, sensitivity to cultural knowledge is part of what makes implicit social cognition substantively distinct from explicit social cognition (Banaji et al., 2004; Gawronski \& Bodenhausen, 2006; Gawronski, 
Peters, \& LeBel, 2008; Nosek \& Hansen, 2008b). An investigation measuring personal attitudes (How much do you like X?) and cultural knowledge (How much does the culture like X?), showed that across about 100 topics only personal attitudes were independently related to the IAT (Nosek \& Hansen, 2008b). Even so, this does not rule out the possibility that cultural experience that is not reflected in self-reported cultural knowledge is influential on implicit measurement.

Other evidence supports the claim that information that is experienced, but not believed, accounts for part of the distinction between implicit and explicit social cognition. Gregg, Seibt, and Banaji (2006) introduced participants to novel groups - one whose members did mostly positive things, the other whose members did mostly negative things. Prior to measuring attitudes toward the groups, participants in one condition were told that there was an error and the information about the groups was backwards - the behaviors performed by one group were actually performed by the other. Participants were able to reverse their explicit evaluations based on the updated knowledge, but implicit evaluations were consistent with the original training. Likewise, explicitly, people resist using the actions of one person to evaluate another person belonging to the same group. However, implicitly, Ranganath and Nosek (2008) found that participants could not resist transferring attitudes formed toward one person to other samegroup members. Moreover, after a multiple-day delay, participants no longer had sufficient memory for the details of who-did-what to separate their explicit evaluations of group members, and both implicit and explicit attitudes formed toward one person transferred to another member of the group. This suggests that what was experienced, but not believed initially, will be believed eventually. This illustrates an interactive process between implicit and explicit social cognition. 
Other substantive moderators. A variety of other moderators of the implicit-explicit relationship exist, though notably, most of the evidence comes from research on attitudes (Hofmann et al., 2005). If there are content differences in moderators by constructs - identity, beliefs, stereotypes, motivations - they have not yet been identified.

Implicit measures were developed, in part, because respondents may be unwilling or unable to report all of the relevant contents of their minds. The unwilling component of this is self-presentation concerns. People may have thoughts or feelings that they recognize, but do not wish to report either because they don't believe them, or because they have concerns about social consequences of reporting such thoughts. Fazio’s MODE model (1990) and subsequent research evidence supported the claim that people may have automatic reactions that are identified by implicit measures, but are adjusted prior to report (Fazio \& Olson, 2003; Nosek, 2005).

However, self-presentation appears to account for only a portion of the difference between implicit and explicit measures. Other factors that moderate the relationship include: (1) elaboration, importance, or strength of the social cognition (Karpinski \& Steinman, 2005) evaluations that are more important or more elaborated show greater consistency between implicit and explicit assessment; (2) distinctiveness, the perception that one's evaluation uniquely identifies the person as different than cultural norms (Nosek, 2005) - more distinct evaluations are associated with stronger implicit-explicit correspondence; and (3) dimensionality, the extent to which the attitude has a simple bi-polar structure with anchors for positive and negative evaluation (Judd \& Kulik, 1980; Nosek, 2005) - simpler structure is associated with stronger implicit-explicit correspondence.

\section{Relations among Implicit Measures}


The prior discussion treats implicit and explicit measures as coherent, unitary assessments of their constructs. They are not. There are a wide variety of implicit measurement procedures and, they may capture distinct components of implicit social cognition. An early study of implicit measures of self-esteem, for example, found that they were weakly related (Bosson et al., 2000). Part of this can be understood as a result of very weak internal consistency of some of the measures (Cunningham et al., 2001). It may also reflect variation in the degree to which the implicit measures are valid assessments of self-esteem. If some measures are less vulnerable to extraneous influences than others, it will be reflected with weaker interrelationships. But, it may also reflect the fact that no single measure assesses all aspects of implicit social cognition, and implicit social cognition may not be a unitary construct. De Houwer (2003), for example, noted that some implicit measurement procedures can be categorized by whether they rely on stimulus-stimulus compatibility or stimulus-response compatibility in measurement. These different procedural factors may draw on distinct psychological processes (Gawronski \& Bodenhausen, 2007).

Despite the lack of consistency among implicit measures being widely recognized, there have been surprisingly few comparative investigations of implicit measures (Bosson et al., 2000; Cunningham et al. 2001; Ranganath, Smith, \& Nosek, 2008; De Houwer \& De Bruycker, 2007). A major task for the next generation of implicit social cognition research will be to understand the relations among implicit measures in an effort to both clarify the operative processes of each, and to improve the taxonomic description of implicit social cognition.

\section{Representations and Processes}

How many representations? The preceding (and later) sections provide evidence justifying a distinction between two forms of social cognition constructs. Implicit and explicit 
social cognitions are related, but distinct, meeting the simultaneous criteria of convergent and divergent validity. This construct distinction, however, does not have direct implications for whether there are one or two mental representations (Nosek \& Smyth, 2007). Theories differ in terms of describing implicit and explicit social cognitions as comprising distinct mental representations (e.g., Strack \& Deutsch, 2004; Wilson et al., 2000), or being a product of distinct processes on a single mental representation (Fazio, 1990; Fazio \& Olson, 2003). Because social cognitions are unobservable constructs, there is no definitive answer to which of these is correct (Greenwald \& Nosek, 2009). Decisions about whether to parse implicit and explicit constructs on the basis of representation, process, or an admixture of the two is based on the parsimony and power of the resulting theoretical description. As described by Nosek and Smyth (2007), both can be used simultaneously without contradiction. The variations of snow, ice, water and steam can be considered multiple representations or a single representation $\left(\mathrm{H}_{2} \mathrm{O}\right)$ interacting with processes such as heating and condensation. Nonetheless, the accumulated evidence suggests that implicit and explicit social cognition are not the same thing, so, whether they use distinct representations, processes, or both, theoretical frameworks are emerging to account for their distinctiveness.

Dual-process theories. The most popular approach for parsing social cognition is to posit at least two modes of cognitive processing - one that is explicit, or deliberate, conscious, effortful, rule-based, reflective, or systematic and another that is implicit, or spontaneous, unconscious, effortless, associative, impulsive, or heuristic (Chaiken \& Trope, 1999; Smith \& DeCoster, 2000). The varieties of theoretical perspectives share the presumption that behavior is a product of the independent and interactive effects of these processes. The framework has been very useful to motivate and organize investigations for when behavior will be influenced by 
something other than the actor's deliberate intentions. Eventually, the variety of perspectives that differ in their details may merge into a common model that predicts when and how implicit and explicit processes influence behavior.

\section{Function: Implicit Social Cognition Predicting Perception, Judgment and Action}

The prior section provided evidence for the construct validity of implicit social cognition as related to but distinct from explicit social cognition. Predictive validity also contributes to construct validation - what the construct does is informative for understanding what it is. Does implicit social cognition predict human behavior? Yes, but how and when is not yet clear.

In a recent meta-analysis of IAT-behavior relations across nine domains (e.g., intergroup behavior, political preferences) with 184 independent samples, both explicit measures $(r=.361)$ and the IAT $(r=.274)$ predicted criterion variables (physiological measures, judgments, and actions; Greenwald, Poehlman, Uhlmann, \& Banaji, 2009). Implicit and explicit social cognitions were positively correlated $(r=.214)$, but both demonstrated predictive validity independent of the other. Prediction was strongest for both implicit $(r=.483)$ and explicit $(r=$ .709) evaluations for political preferences. Explicit measures were a better predictor than the IAT overall, though the IAT outperformed explicit measures in socially sensitive domains like race and intergroup behavior (IAT $r$ 's $=.236, .201$; explicit $r$ 's $=.118, .120$ ). Also, predictive validity was stronger for both implicit and self report in domains in which implicit-explicit correlations were strong. This could mean that consistency between the two constructs is mutually reinforcing for influencing behavior (Greenwald et al., 2009).

This meta-analysis organized the evidence for predictive validity by the topic of study. Here, we complement that meta-analysis with two alternative organizational schemes. We first review evidence that implicit social cognitions predict within-the-person variables (such as brain 
activity, physiological responses, or perception), social or interpersonal variables (such as social judgment and action), and group-level variables (such as national estimates of implicit social cognitions predicting cultural differences). Second, we identify conditions that moderate the extent to which implicit social cognition predicts behavior, such as whether the behavior is spontaneous or subject to social desirability concerns (see also Perugini, Richetin, \& Zogmaister, 2010).

\section{Predicting Variables within the Person to across Cultures}

Intrapersonal variables. Correlates of neurological activity are predicted by implicit cognition. For example, the amygdala is associated with emotion processing and evaluation. Cunningham, et al. (2004) found stronger amygdala activation after a brief presentation (30 ms) of Black faces compared to White faces, and the strength of the activation pattern was predicted by the individual's implicit preferences for Black compared to White people (see also Phelps, et al., 2000). Notably, when the presentation time was extended (525 ms), differential amygdala activation for Black and White faces no longer occurred, but differences were observed in the prefrontal cortex and anterior cingulate, areas associated with inhibitory control. These results provide converging evidence that implicit measures reflect automatic responses that may be inhibited or otherwise altered by control processes (Cunningham, et al., 2004; see also Quadflieg et al., 2009; Richeson, et al., 2003).

Implicit cognition predicts physiological and hormonal responses in social and intergroup contexts. Implicit anxiety (associating self with anxious) predicted increased systolic and diastolic blood pressure and heart rate during and after a stressful speech preparation and delivery (Egloff, Wilhelm, Neubauer, Mauss, \& Gross, 2002). Low levels of implicit racial bias predicted increased release of the hormone dehydroepiandrosterone (DHEA) sulfate, which is 
thought to manage stress levels, during an interracial interaction. The researchers interpreted this finding to suggest that egalitarian attitudes may have adaptive effects for managing stress in interracial interactions (Mendes, Gray, Mendoza-Denton, Major, \& Epel, 2007). Similarly, PageGould, Mendoza-Denton, and Tropp (2008) simulated friendship-building in the lab over a 3week period and found that people with high levels of implicit racial bias had higher levels of cortisol - a hormone activated in response to stressors - following the initial interracial interaction, but they showed decreased cortisol levels over the course of developing the interracial friendship.

Implicit cognition also predicts visual perception. Hugenberg and Bodenhausen (2003) showed participants short video clips of Black or White faces that were initially very angry but became neutral and then happy. Participants' pressed a key when they perceived the angry facial expression to be gone. Implicit racial attitudes, but not explicit racial attitudes, predicted the speed of detecting the emotion change, but only for the Black faces, suggesting that the visual perception of anger lingers longer when associated with Black faces than White faces, and this is moderated by implicit attitudes (Hugenberg \& Bodenhausen, 2003).

Social judgments and actions. Most evidence for the predictive validity of implicit social cognition assesses social judgments and actions. Early investigations of implicit social cognition primarily concerned intergroup bias, particularly race bias. Interest in predicting these behaviors with implicit measures continues, presumably because of the lack of success in predicting them with explicit measures. For example, stronger implicit preferences for Whites over Latinos predicts stronger support for exclusionary immigration policy proposals (Perez, 2010), the combination of implicit and explicit race bias of physicians predicted their patients' satisfaction with patient-physician interaction (Penner et al., 2010), implicit bias against 
intravenous drug users among nurses working with that population predicted their intention to change jobs (von Hippel et al., 2008), and hiring managers' implicit Arab-Swedish (Rooth, 2010) and Obese-Thin (Agerstrom \& Rooth, 2011) biases predicted likelihood of inviting Arab and obese job applicants for an interview.

As measurement has diversified, so has the application to other areas of social judgment and behavior. For example, implicit positivity toward risk-taking behavior among pilots predicted risky behavior in flight simulation tests (Molesworth \& Chang, 2009), implicit associations of self with collaboration predicted employees' collaborative engagement in a firm (Srivastava \& Banaji, 2011), implicit romantic attraction to one's partner predicted relationship longevity (Lee, Rogge, \& Reis, 2009), implicit moral attitudes predicted decisions during a decision-making exercise about business ethics (Marquardt \& Hoeger, 2009), stronger implicit associations of science with male predicted weaker engagement and achievement in science (Nosek \& Smyth, 2011), implicit self-positivity predicted self-selected seating distance from someone with the same initials (Kocan \& Curtis, 2009), and implicit associations of self with aggressiveness among semi-professional basketball players predicted their playing time and game performance (Teubel, Asendorpf, Banse, \& Schnabel, 2011). These illustrate a remarkable diversity in areas of application and predictive validity, and they anticipate the growth of application of implicit measures to business, education, relationships, and human factors.

Health and medicine are well-ahead of these areas in the breadth of application of implicit measures, as well as the accumulated evidence for predictive validity. For example, stronger implicit associations of self with death predicted greater likelihood of a suicide attempt in the following six months among psychiatric ER patients (Nock et al., 2010; see also Glashouwer \& de Jong, 2010), implicit associations about panic predicted symptom severity and 
behavioral distress among a sample of people with panic disorder (Teachman, Smith-Janik, \& Saporito, 2007), implicit self-stigma and associations of mental illness with shame or guilt among people with affective disorders or schizophrenia predicted disorder-related beliefs and quality of life (Rusch et al., 2010), and implicit associations with alcohol, tobacco, and drugs predict addiction-related behavior (Chassin, Presson, Sherman, Seo, \& Macy, 2010; Payne, McClernon, \& Dobbins, 2007; Wiers et al., 2010).

Group-level variables. The preceding examples all concern implicit social cognitions predicting individual behavior. Aggregating implicit social cognition in a group, region, or culture may provide insight into variations across groups and cultures that are not manifested in explicit cultural beliefs. For example, Nosek, et al. (2009) found that variation across nations' implicit stereotypes associating men with science more than women with science predicted sex differences in science achievement across those nations, even after controlling for national differences in explicit gender stereotypes.

\section{Toward a Model: Conditions That Moderate Predictive Validity of Implicit Social}

\section{Cognition}

The evidence for the predictive validity of implicit social cognition is plentiful, but the field has not yet produced an effective model of when and how implicit cognitions will predict behavior. Here, we identify factors that have some empirical support as moderators of implicitbehavior relations. Explicit social cognitions are expected to direct behavior when the individual has the motivation to deliberately direct behavior, the opportunity to initiate relevant actions, the ability to control the actions, and the awareness of the factors that are influencing the actions (Nosek et al., 2011). To the extent that any of these factors are not employed effectively, implicit social cognition may become a better predictor of behavior. 


\section{Introspective access and self-presentational concerns. Implicit measures were} invented because researchers believed that social cognitions exist that people are unable or unwilling to report. Inability refers primarily to a lack of awareness of the content, and unwillingness refers primarily to a motivation to report content that is accessible but personally or socially inadvisable to report. For example, people are hesitant to report liking or doing illegal or stigmatized behaviors, such as marijuana (Ames, et al., 2010) and tobacco use (Sherman, et al., 2009), and violent tendencies among at-risk offenders in a treatment program (Polaschek, Bell, Calvert, Takarangi, 2010). In these cases, implicit measurement predicts behavior better than self report. Likewise, self-presentation concerns are usually strong for interracial and intergroup behavioral contexts, as evidenced by Greenwald and colleagues’ (2009) findings that the IAT predicted outcomes better than self reported preferences in these domains, and findings such as implicit racial attitudes predicting support for Barack Obama and his policies (Greenwald, Smith, et al., 2009; Knowles, Lowery, Schaumberg, 2010; Payne, et al., 2010). In all these cases, it is difficult to distinguish whether the comparative lack of predictive validity for explicit measures is evidence of introspective failure or self-presentation. It could be that people are unaware of their implicit cognitions or are unaware of the link between the implicit cognition and the behavior. It could also be that people have some kind of relevant introspective experience but fail to report it. We suspect that both occur and depend on conditions that are not yet known.

Spontaneous versus deliberate behavior. People may be motivated to behave in a particular way, and even be aware of the mental contents that may influence their behavior, but nonetheless fail to behave as intended because they do not have the opportunity to initiate deliberate actions (Fazio, 1990). For example, nonverbal behavior is understood to be much 
more difficult to control than the content of one's speech. In interracial interactions, Dovidio, Kawakami, and Gaertner (2002) found that implicit racial attitudes predicted nonverbal behavior (e.g., blinking rate, amount of eye contact), but explicit racial attitudes did not. Simultaneously, explicit racial attitudes predicted verbal behavior, but implicit racial attitudes did not (see also Fazio et al., 1995; McConnell \& Leibold, 2001).

Rudolph, Schröder-Abé, Riketta, and Schütz (2010) found that implicit self-esteem - but not explicit self-esteem predicted experimenter-rated anxiety and spontaneous self-confident behaviors in anxiety-producing situations. And, explicit self-esteem, but not implicit self-esteem, predicted self-reported anxiety and controlled self-confidence behaviors during the same tasks. Asendorpf, Banse, and Mücke (2002) found a similar pattern of implicit and explicit shyness differentially predicting spontaneous and deliberate behaviors in an interpersonal context.

These examples could be the basis for a very simple model - implicit processes predict spontaneous behavior and explicit processes predict deliberate behavior. This is too simplistic. On the one hand, explicit goal setting in advance can automate behavioral responses when the relevant context occurs (Gollwitzer, 1999). This gives explicit processes some influence over spontaneous behavior "at a distance." But, even more damaging for the simple hypothesis is evidence that implicit social cognition can add incremental predictive validity beyond explicit social cognition even for highly deliberate behaviors. For example, voting may be the prototypical deliberate behavior - people know that it is occurring well in advance, there is ample opportunity for processing the relevant information to decide one's vote, and the person must initiate planned actions in order to carry out the vote. Nonetheless, multiple studies find that voting is predicted by implicit social cognitions beyond what is accounted for by explicit measures (Friese, Bluemke, \& Wanke, 2007; Greenwald et al., 2009; Payne et al., 2010), 
particularly when the person reported being undecided prior to the vote (Galdi, et al., 2008;

Roccato \& Zogmaister, 2010). As such, the present state of evidence suggests that spontaneity contributes to understanding when implicit social cognition will predict behavior, but it is not the exclusive influence.

Cognitive resources and self-regulation. Whereas spontaneity emphasizes the opportunity to control one's response, the availability of cognitive resources and self-regulation emphasizes the ability to control that response even if it does not occur spontaneously or rapidly. For example, there are individual differences in working memory capacity, the ability to hold multiple pieces of information in mind for complex thinking and reasoning, suggesting that there may be individual differences in the ability to exert deliberate control over one's behavior. Thush, et al. (2008) found that among a group of high-risk youth, implicit alcohol associations predicted alcohol use one month later more strongly for individuals with low working memory capacity (WMC) than high WMC, whereas the reverse was true for explicit alcohol associations. In other domains, when cognitive processing resources were depleted, implicit attitudes toward potato chips predicted consumption of chips, whereas explicit attitudes predicted eating chips when resources were not depleted (Friese, Hofmann, \& Wänke, 2008). Likewise, reducing cognitive processing resources increased the predictive validity of implicit racial attitudes in an interracial interaction (Hofmann, Gschwendner, Castelli, \& Schmitt, 2008).

In summary, the predictive validity evidence suggests that implicit and explicit social cognitions each contribute to many aspects of human behavior. The next challenge for the field is to converge on a model that anticipates under what conditions each will show predictive validity, and to explain how implicit and explicit processes work independently or interactively to produce behavior (e.g., Strack \& Deutsch, 2004). 


\section{Formation, Malleability, and Change}

The preceding sections evaluate implicit social cognitions as they operate during the moment of measurement. Just as it is not possible to understand a film by looking at individual frames, it is not possible to understand implicit social cognition without examining its structure and function over time. The development of implicit social cognition over the lifespan is virtually uncharted territory (Olson \& Dunham, 2010). And, of the research that has been done, very little of it actually investigates development - formation and change over time. Rather, most "developmental" studies are cross-sectional investigations using samples of children. These studies highlight the importance of taking development seriously. Across the lifespan, the understanding of "what is implicit?" and the interaction of implicit and explicit processes may change (Olson \& Dunham, 2010). Does infant cognition fit dual-process notions, or - for example - do explicit processes have a developmental trajectory? Likewise, longitudinal investigations of aging suggest that a variety of cognitive functions that should be related to implicit cognition change (Salthouse, 2010). This could lead to distinct operative processes at different points of the lifespan or, at least, shifts in the interaction and functioning of explicit and implicit processes (e.g., Gonsalkorale \& Sherman, 2009; Stewart, von Hippel, \& Radvansky, 2009). Failing to take stock of the development of implicit social cognition will retard progress in development of effective theories of its structure and function.

Despite the lack of developmental research, there is a healthy literature on formation, malleability and change of implicit social cognition (Blair, 2002; Gawronski \& Sritharan, 2010). Perhaps the key insight from this research is its contrast to early models that emphasized how mental contents that could be activated automatically were slow to form, relatively insensitive to situational features, and slow to change (e.g., Schneider \& Shiffrin, 1977; Smith \& DeCoster, 
2000). Each of these ideas has been challenged, to some degree, by recent findings in implicit social cognition.

\section{Formation}

Implicit social cognitions can form very rapidly. A variety of demonstrations show that in the context of a single experimental session, implicit social cognitions can be created via evaluative conditioning (see Hofmann, De Houwer, Perugini, Baeyens, \& Crombez, 2010 for a review), minimal group manipulations (e.g., Ashburn-Nardo, et al., 2001; Paladino \& Castelli, 2008), and associating the novel object with the self (e.g., Prestwich, Perugini, Hurling, \& Richetin, 2010). And, even with a training session of less than five minutes, evaluations formed toward novel groups can persist for at least a week (Ranganath \& Nosek, 2008), perhaps much longer.

Given how quickly they form, an interesting follow-up question is how little information is necessary to form an implicit evaluation? Gawronski, Walther, and Blank (2005) used as few as three descriptive statements to create implicit evaluations toward a novel target. Greenwald, Pickrell, and Farnham (2002) found that people formed an implicit preference for a hypothetical group after just reading the names of its members. De Houwer, Beckers, and Moors (2007) found that merely suggesting that one would be learning positive information about one group and negative information about another was sufficient to elicit an implicit preference for the former. They interpreted this to indicate that the observed effects were faked, but other evidence suggests that the instruction actually formed an attitude (Bar-Anan, Ratliff, \& Nosek, 2011). This pushes the boundary to a minimum of experience with a concept to form implicit evaluations of it. But, even that may not be the lower limit. Duckworth, Bargh, Garcia, and Chaiken (2002) found that implicit evaluations could be measured for targets that had never been experienced 
previously. Van Leeuwen and Macrae (2004; see also Richetin, Croizet, \& Huguet, 2004) showed that features of novel items (e.g., attractiveness of faces) affected implicit evaluations. Gregg, Seibt, \& Banaji. (2006) had to conduct extensive pretesting of implicit evaluations of novel groups to find two that were evaluated similarly. And, providing some insight on how automatic evaluations might exist for targets for which there is little to no direct experience, Walther (2002) found that conditioning evaluations to one target could transfer to other targets that were associated with the conditioned target. Rapid assessments of similarity with previously experienced social content may drive automatic evaluation of novel social objects.

\section{Malleability}

The remarkable simplicity of forming new associations, and evidence that implicit evaluation can occur toward concepts that have never been experienced previously, makes it easy to anticipate that implicit social cognitions are quite malleable. This was not always so easy to imagine. Early conceptualizations of automaticity seemed to consider it akin to fixed action patterns. Once automatized, the same response would occur each time it was activated and be relatively insensitive to the social context. Gawronski and Sritharan (2010) reviewed many factors that elicit shifts in implicit social cognition including (1) the context of evaluation suggesting that a target was more or less positive (Barden et al., 2004; Wittenbrink et al., 2001), (2) making information about target concepts salient such as positive exemplars, roles or memories of one group and negative exemplars, roles or memories of a comparison group (Dasgupta \& Greenwald, 2001; Mitchell et al., 2003; Sassenberg \& Wieber, 2005), (3) increasing participants motivation to affiliate with another person whose beliefs are apparent (Sinclair, Lowery, Hardin, \& Colangelo, 2005), and (4) altering the participants' state such as eliciting greater positivity toward smoking among deprived than non-deprived smokers (Sherman, et al., 
2003; Payne, et al., 2007) and higher levels of implicit bias among threatened than nonthreatened participants (Gonsalkorale, Carlisle, \& von Hippel, 2007; Rudman, Dohn, \& Fairchild, 2007). A full review of the present literature might lead one to conclude that there is very little stability in implicit social cognition and effects are very sensitive to the social context. That may well be true. However, partly because of the historical emphasis on stability, and partly because of prejudice against the null hypothesis (Greenwald, 1975), the present literature may overestimate malleability. It is less likely that studies of malleability that elicit no difference across situations will be reported (but see Joy-Gaba \& Nosek, 2010; Schmidt \& Nosek, 2010). With a literature biased toward confirmation of malleability, it will be more difficult to generate an effective theoretical model for when malleability will, and will not, occur.

At present, the model best prepared to account for malleability effects is the AssociativePropositional Evaluation (APE) Model (Gawronski \& Bodenhausen, 2006). The APE model provides an organizing framework for predicting when implicit social cognitions will be malleable, particularly in comparison to explicit social cognitions. Associative processes are the activation of associations based on past experience. Propositional processes involve the validation of information that is based on these associations - i.e., deciding whether it is true or false. Implicit measures are presumed to reflect the outcome of associative activations and explicit measures reflect the outcome of propositional thinking. This model thus anticipates multiple routes to malleability and change of implicit social cognition. In particular, manipulations that shift association strengths or make accessible different associations should be effective on implicit measures alone if the respondent rejects the new information as false (e.g., Gawronski \& LeBel, 2008), but on both implicit and explicit measures if the information is accepted as true (e.g., Whitfield \& Jordan, 2009). Further, manipulations that initiate 
propositional processing and lead to new associations that are consistent with that processing should affect both implicit and explicit measures (e.g., Gawronski \& Walther, 2008), but if the propositional processing leads the person to reject an existing association as false, then explicit measures alone should be affected (Gregg et al., 2006). This model should apply both to malleability and change.

\section{Change}

One way to conceive of the difference between malleability and change is that the former are shifts that are bounded by the circumstances of measurement, and the latter are shifts that persist beyond the immediate setting. By this definition, there is surprisingly little research on change in implicit social cognition. Almost all research on shifting implicit social cognition occurs within a single laboratory session during which both the manipulation and measurement are completed. However, there is comparatively little evidence for change that persists beyond the immediate experimental context (exceptions include Dasgupta \& Greenwald, 2001; Kawakami et al., 2000; Olson \& Fazio, 2006).

The exceptions to this trend illustrate that changing implicit social cognition is possible, but do not clarify whether it is the case that minimal manipulations that are sufficient for formation or to elicit malleability effects will be similarly effective for eliciting change. Most of the documented evidence for change involves intensive interventions such as: weeks of cognitive behavioral therapy for spider phobia showing change on implicit spider fear 2 months after therapy (Teachman \& Woody, 2003), changing implicit racial biases following a semester long experience with a diversity education course (Rudman, Ashmore, \& Gary, 2001) or a Black roommate (Shook \& Fazio, 2008), having female instructors changing implicit gender stereotypes over the course of a semester (Dasgupta \& Asgari, 2004; Stout, Dasgupta, 
Hunsinger, \& McManus, 2011), and a social competence training program changing implicit aggressiveness at a follow-up session four months later (Gollwitzer, Banse, Eisenbach, \& Naumann, 2007). Some cross-sectional studies also suggest evidence of change from naturally occurring events such as an apparent decline in implicit preferences for White compared to Black people following the candidacy of Barack Obama for U.S. president (Plant et al., 2009; but see Schmidt \& Nosek, 2010).

Unlike the other sections of this chapter, the evidence of change summarized here is not a small sampling of large pool of citations. This subsection cites most of the evidence for "real" change. It may well be the case that many of the factors that have been shown to impact implicit measures within a single session will show lasting effect. But, it could also be that some manipulations are "merely" situational effects and others are long-lasting. Explaining when and how malleability and change effects will differ is virtually uncharted theoretical territory.

\section{Conclusion and What's Next?}

As a discipline, implicit social cognition materialized following Greenwald and Banaji’s (1995) review and the invention of EP and the IAT. The rapid ascension into a field deserving a chapter in the Handbook of Social Cognition is illustrated by citation patterns in the Journal of Personality and Social Psychology. Two articles about implicit social cognition were among the top 100 cited articles in that journal during the 1980's. In both the 1990's and 2000's, the first, fourth, and ninth most cited articles of the decade were about implicit social cognition (retrieved from Publish or Perish, February 28, 2011). The present evidence provides a foundation of construct validity for the next generation of research questions including identification of the mechanisms underlying implicit measures (De Houwer et al., 2009), developing a theoretical model for the independent and interactive effects of implicit and explicit processes in producing 
social behavior, clarification of when and how implicit social cognitions will be altered by the situation and amenable to change, and understanding how implicit and explicit processes develop across the lifespan. Likewise, whereas implicit social cognition theory and evidence is established already in social psychology, its application to problems in neighboring disciplines has begun and is accelerating (e.g., Nosek, Graham, \& Hawkins, 2010; Perkins \& Forehand, 2010; Snowden \& Gray, 2010; Teachman, Cody, \& Clerkin, 2010; Wiers et al, 2010). One of the most intriguing issues concerns the potential for implicit social cognition research to impact law, public policy, and organizational practices (Chugh, 2004; Greenwald \& Kreiger, 2006; Jost et al., 2009; Lane, Kang, \& Banaji, 2007; Tetlock \& Mitchell, 2009). What, for example, are the implications of behavior being shaped by thoughts and feelings that exist outside of conscious awareness and control for legal theory that places such a strong emphasis on intent as a determinant of responsibility and culpability? Such questions confront the basic researcher to consider how all this research matters.

\section{References}

Agerström, J., \& Rooth, D. (in press). The role of automatic obesity stereotypes in real hiring discrimination. The Journal of Applied Psychology.

Ames, S.L., Grenard, J.L., Thush, C., Sussman, S., Wiers, R.W., \& Stacy, A.W. (2007). Comparison of indirect assessments of association as predictors of marijuana use among at-risk adolescents. Experimental and Clinical Psychopharmacology, 15(2), 204-218.

Arkes, H.R., \& Tetlock, P.E. (2004). Attributions of implicit prejudice, or "would Jesse Jackson 'fail' the Implicit Association Test?". Psychological Inquiry, 15(4), 257-278.

Asendorpf, J.B., Banse, R., \& Mücke, D. (2002). Double dissociation between implicit and explicit personality self-concept: The case of shy behavior. Journal of Personality and Social Psychology, 83(2), 380-393.

Ashburn-Nardo, L., Voils, C.I., \& Monteith, M.J. (2001). Implicit associations as the seeds of intergroup bias: How easily do they take root? Journal of Personality and Social Psychology, 81(5), 789-799.

Banaji, M.R. (2001). Implicit attitudes can be measured. In H.L. Roediger, J.S. Nairne, I. Neath, \& A.M. Surprenant (Eds.), The nature of remembering: Essays in honor of Robert $G$. Crowder (pp. 117-150). Washington, DC: American Psychological Association.

Banaji, M.R., Nosek, B.A., \& Greenwald, A.G. (2004). No place for nostalgia in science: A response to Arkes and Tetlock. Psychological Inquiry, 15(4), 279-310. 
Bar-Anan, Y., \& Nosek, B.A. (2010). Perceptions of intentionally causing unintentional attitude effects: The case of the Affective Misattribution Procedure. Unpublished manuscript.

Bar-Anan, Y., Nosek, B.A., \& Vianello, M. (2009). The sorting paired features task: A measure of association strengths. Experimental Psychology, 56(5), 329-343.

Barden, J., Maddux, W.W., Petty, R.E., \& Brewer, M.B. (2004). Contextual moderation of racial bias: The impact of social roles on controlled and automatically activated attitudes. Journal of Personality and Social Psychology, 87(1), 5-22.

Bargh, J.A. Chaiken, S., Govender, R., \& Pratto, F. (1992). The generality of the automatic attitude activation effect. Journal of Personality and Social Psychology, 62, 893-912.

Bem, D.J. (1967). Self-perception: An alternative interpretation of cognitive dissonance phenomena. Psychological Review, 74(3), 183-200.

Blair, I.V. (2002). The malleability of automatic stereotypes and prejudice. Personality and Social Psychology Review, 6(3), 242 -261.

Blanton, H., Jaccard, J., Gonzales, P.M., \& Christie, C. (2006). Decoding the implicit association test: Implications for criterion prediction. Journal of Experimental Social Psychology, 42(2), 192-212.

Bosson, J.K., Swann, W.B., \& Pennebaker, J.W. (2000). Stalking the perfect measure of implicit self-esteem: The blind men and the elephant revisited? Journal of Personality and Social Psychology, 79(4), 631-643.

Brendl, C.M., Markman, A.B., \& Messner, C. (2005). Indirectly measuring evaluations of several attitude objects in relation to a neutral reference point. Journal of Experimental Social Psychology, 41(4), 346-368.

Brown, A.S., Gray, N.S., \& Snowden, R.J. (2009). Implicit measurement of sexual associations in child sex abusers: Role of victim type and denial. Sexual Abuse, , 21(2), 166-180.

Cai, H., Sriram, N., Greenwald, A.G., \& McFarland, S.G. (2004). The Implicit Association Test's D measure can minimize a cognitive skill confound: Comment on McFarland and Crouch (2002). Social Cognition, 22, 673-684.

Campbell, D.T., \& Fiske, D.W. (1959). Convergent and discriminant validation by the multitraitmulti method matrix. Psychological Bulletin, 56, 81-105.

Chaiken, S. and Trope, Y. (Eds.) (1999) Dual-process theories in social psychology. New York: Guilford.

Chassin, L., Presson, C.C., Sherman, S.J., Seo, D., \& Macy, J.T. (2010). Implicit and explicit attitudes predict smoking cessation: Moderating effects of experienced failure to control smoking and plans to quit. Psychology of Addictive Behaviors, 24(4), 670-679.

Chugh, D. (2004). Societal and managerial implications of implicit social cognition: Why milliseconds matter. Social Justice Research, 17(2), 203-222.

Conrey, F.R., Sherman, J.W., Gawronski, B., Hugenberg, K., \& Groom, C. J. (2005). Separating multiple processes in implicit social cognition: The quad model of implicit task performance. Journal of Personality and Social Psychology, 89(4), 469-487.

Cronbach, L.J. \& Meehl, P.E. (1955). Construct validity in psychological tests. Psychological Bulletin, 52, 281-302.

Cunningham, W.A., Preacher, K.J., \& Banaji, M.R. (2001). Implicit attitude measures: Consistency, stability, and convergent validity. Psychological Science, 12(2), 163-70.

Cunningham, W.A., Johnson, M.K., Raye, C.L., Gatenby, J.C., Gore, J.C., \& Banaji, M.R. (2004). Separable neural components in the processing of Black and White faces. Psychological Science, 15(12), 806 -813. 
Cvencek, D., Greenwald, A.G., Brown, A., Snowden, R., Gray, N. (in press). Faking of the Implicit Association Test is statistically detectable and partly correctable. Basic and Applied Social Psychology.

Dasgupta, N., \& Greenwald, A.G. (2001). On the malleability of automatic attitudes: combating automatic prejudice with images of admired and disliked individuals. Journal of Personality and Social Psychology, 81(5), 800-814.

Dasgupta, N., \& Asgari, S. (2004). Seeing is believing: Exposure to counterstereotypic women leaders and its effect on automatic gender stereotyping. Journal of Experimental Social Psychology, 40, 642-658.

De Houwer, J. (2003a). A structural analysis of indirect measures of attitudes. In J. Musch \& K.C. Klauer (Eds.), The psychology of evaluation: Affective processes in cognition and emotion. (pp. 219-244). Mahwah, NJ: Lawrence Erlbaum Associates.

De Houwer, J. (2003b). The Extrinsic Affective Simon Task. Experimental Psychology, 50(2), 77-85.

De Houwer, J., Beckers, T., \& Moors, A. (2007). Novel attitudes can be faked on the Implicit Association Test. Journal of Experimental Social Psychology, 43(6), 972-978.

De Houwer, J., \& De Bruycker, E. (2007). The implicit association test outperforms the extrinsic affective Simon task as an implicit measure of inter-individual differences in attitudes. British Journal of Social Psychology, 46(2), 401-421.

De Houwer, J. \& Moors, A. (2010). Implicit measures: Similarities and differences. In B. Gawronski and B. K. Payne (Eds.), Handbook of Implicit Social Cognition (pp. 176-196) New York, NY: Guilford.

De Houwer, J., Teige-Mocigemba, S., Spruyt, A., \& Moors, A. (2009). Implicit measures: A normative analysis and review. Psychological Bulletin, 135(3), 347-368.

DeHart, T., Pelham, B.W., \& Tennen, H. (2006). What lies beneath: Parenting style and implicit self-esteem. Journal of Experimental Social Psychology, 42(1), 1-17.

Dovidio, J.F., Kawakami, K., \& Gaertner, S.L. (2002). Implicit and explicit prejudice and interracial interaction. Journal of Personality and Social Psychology, 82(1), 62-68.

Duckworth, K.L., Bargh, J.A., Garcia, M., \& Chaiken, S. (2002). The automatic evaluation of novel stimuli. Psychological Science, 13(6), 513-519.

Egloff, B., Wilhelm, F.H., Neubauer, D.H., Mauss, I.B., \& Gross, J.J. (2002). Implicit anxiety measure predicts cardiovascular reactivity to an evaluated speaking task. Emotion, 2(1), 3-11.

Fazio, R.H. (1990). Multiple processes by which attitudes guide behavior: The MODE model as an integrative framework. In M.P. Zanna (Ed.), Advances in experimental social psychology (Vol. 23, pp. 75-109). New York: Academic Press.

Fazio, R.H., Jackson, J.R., Dunton, B.C., \& Williams, C.J. (1995). Variability in automatic activation as an unobtrusive measure of racial attitudes: A bona fide pipeline? Journal of Personality and Social Psychology, 69(6), 1013-1027.

Fazio, R.H., \& Olson, M.A. (2003). Implicit measures in social cognition research: Their meaning and use. Annual Review of Psychology, 54(1), 297-327.

Fazio, R.H., Sanbonmatsu, D.M., Powell, M.C., \& Kardes, F.R. (1986). On the automatic activation of attitudes. Journal of Personality and Social Psychology, 50(2), 229-238.

Ferguson, M.J. (2007). On the automatic evaluation of end-states. Journal of Personality and Social Psychology, 92, 596-611.

Festinger, L. (1957). A theory of cognitive dissonance. Stanford University Press. 
Fiedler, K., \& Bluemke, M. (2005). Faking the IAT: Aided and unaided response control on the Implicit Association Tests. Basic \& Applied Social Psychology, 27(4), 307-316.

Franck, E., Raedt, R.D., \& Houwer, J.D. (2007). Implicit but not explicit self-esteem predicts future depressive symptomatology. Behaviour Research and Therapy, 45(10), 24482455.

Freud, S. (1900/1972). Interpretation of dreams. New York: Basic Books.

Friese, M., Bluemke, M., \& Wänke, M. (2007). Predicting voting behavior with implicit attitude measures: The 2002 German parliamentary election. Experimental Psychology, 54(4), 247-255.

Friese, M., Hofmann, W., \& Wänke, M. (2008). When impulses take over: Moderated predictive validity of explicit and implicit attitude measures in predicting food choice and consumption behaviour. The British Journal of Social Psychology, 47(3), 397-419.

Galdi, S., Arcuri, L., \& Gawronski, B. (2008). Automatic mental associations predict future choices of undecided decision-makers. Science, 321(5892), 1100-1102.

Gawronski, B. \& Bodenhausen, G.V. (2005) Accessibility effects on implicit social cognition: The role of knowledge activation versus retrieval experiences. Journal of Personality and Social Psychology, 89, 672-685

Gawronski, B., \& Bodenhausen, G.V. (2006). Associative and propositional processes in evaluation: An integrative review of implicit and explicit attitude change. Psychological Bulletin, 132(5), 692-731.

Gawronski, B., \& LeBel, E.P. (2008). Understanding patterns of attitude change: When implicit measures show change, but explicit measures do not. Journal of Experimental Social Psychology, 44(5), 1355-1361.

Gawronski, B., \& Payne, B.K. (2010). Handbook of implicit social cognition: Measurement, theory, and applications. Guilford Press.

Gawronski, B., Peters, K.R., \& LeBel, E.P. (2008). What makes mental associations personal or extra-personal? Conceptual issues in the methodological debate about implicit attitude measures. Social and Personality Psychology Compass, 2(2), 1002-1023.

Gawronski, B., \& Sritharan, R. (2010). Formation, change and contextualization of mental associations: Determinants and principles of variations in implicit measures. In B. Gawronski \& B.K. Payne (Eds.), Handbook of Implicit Social Cognition: Measurement, Theory, and Applications. New York, NY: Guilford Press.

Gawronski, B., \& Walther, E. (2008). The TAR effect: When the ones who dislike become the ones who are disliked. Personality \& Social Psychology Bulletin, 34(9), 1276-1289.

Gawronski, B., Walther, E., \& Blank, H. (2005). Cognitive consistency and the formation of interpersonal attitudes: Cognitive balance affects the encoding of social information. Journal of Experimental Social Psychology, 41(6), 618-626.

Glashouwer, K.A., \& de Jong, P.J. (2010). Disorder-specific automatic self-associations in depression and anxiety: Results of the Netherlands study of depression and anxiety. Psychological Medicine, 40(07), 1101-1111.

Gollwitzer, M., Banse, R., Eisenbach, K., \& Naumann, A. (2007). Effectiveness of the vienna social competence training on explicit and implicit aggression: Evidence from an aggressiveness-IAT. European Journal of Psychological Assessment, 23(3), 150-156.

Gollwitzer, P.M. (1999). Implementation intentions: Strong effects of simple plans. American Psychologist, 54(7), 493-503. 
Gonsalkorale, K., Carlisle, K., \& von Hippel, W. (2007). Intergroup threat increases implicit stereotyping. International Journal of Psychology and Psychological Therapy, 7, 189200.

Gonsalkorale, K., Sherman, J.W., \& Klauer, K.C. (2009). Aging and prejudice: Diminished regulation of automatic race bias among older adults. Journal of Experimental Social Psychology, 45(2), 410-414.

Govan, C.L., \& Williams, K.D. (2004). Changing the affective valence of the stimulus items influences the IAT by re-defining the category labels. Journal of Experimental Social Psychology, 40(3), 357-365.

Gray, N.S., Brown, A.S., MacCulloch, M.J., Smith, J., \& Snowden, R.J. (2005). An implicit test of the associations between children and sex in pedophiles. Journal of Abnormal Psychology, 114(2), 304-308.

Greenwald, A.G. (2001). Nothing so practical as a good method. Invited address at meeting of the Person Memory Interest Group, Coeur d'Alene, ID.

Greenwald, A.G., \& Banaji, M.R. (1995). Implicit social cognition: Attitudes, self-esteem, and stereotypes. Psychological Review, 102(1), 4-27.

Greenwald, A.G., Banaji, M.R., Rudman, L.A., Farnham, S.D., Nosek, B.A., \& Mellott, D.S. (2002). A unified theory of implicit attitudes, stereotypes, self-esteem, and self-concept. Psychological Review, 109(1), 3-25.

Greenwald, A.G., \& Krieger, L.H. (2006). Implicit bias: Scientific foundations. California Law Review, 94(4), 945-967.

Greenwald, A.G., McGhee, D.E., \& Schwartz, J.L.K. (1998). Measuring individual differences in implicit cognition: The implicit association test. Journal of Personality and Social Psychology, 74(6), 1464-1480.

Greenwald, A.G., Nosek, B.A., \& Banaji, M.R. (2003). Understanding and using the Implicit Association Test: I. An improved scoring algorithm. Journal of Personality and Social Psychology, 85(2), 197-216.

Greenwald, A.G., Ostrom, T.M., C,H., Fishbein, M., \& Rubin, Z. (1975). Consequences of prejudice against the null hypothesis. Psychological Bulletin, 82, 1--20.

Greenwald, A.G., Pickrell, J.E., \& Farnham, S.D. (2002). Implicit partisanship: Taking sides for no reason. Journal of Personality and Social Psychology, 83(2), 367-379.

Greenwald, A.G., Poehlman, T.A., Uhlmann, E.L., \& Banaji, M.R. (2009). Understanding and using the Implicit Association Test: III. Meta-analysis of predictive validity. Journal of Personality and Social Psychology, 97(1), 17-41.

Greenwald, A.G., \& Ronis, D.L. (1978). Twenty years of cognitive dissonance: Case study of the evolution of a theory. Psychological Review, 85(1), 53-57.

Greenwald, A.G., Smith, C.T., Sriram, N., Bar-Anan, Y., \& Nosek, B.A. (2009). Race attitude measures predicted vote in the 2008 U. S. Presidential Election. Analysis of Social Issues and Public Policy, 9, 241-253.

Gregg, A.P., Seibt, B., \& Banaji, M.R. (2006). Easier done than undone: Asymmetry in the malleability of implicit preferences. Journal of Personality and Social Psychology, 90(1), $1-20$.

Harmon-Jones, E. \& Mills, J. (Eds.) (1999). Cognitive dissonance: Progress on a pivotal theory in social psychology. Washington, DC: American Psychological Association.

Helmholtz, H.. (1925). Treatise on physiological optics ( $3^{\text {rd }}$ ed., Vol. 3; J.P.C. Southall, Trans.). Menasha, WI: Banta. (Original $3^{\text {rd }}$ ed. published 1910). 
Hetts, J.J., Sakuma, M., \& Pelham, B.W. (1999). Two roads to positive regard: Implicit and explicit self-evaluation and culture. Journal of Experimental Social Psychology, 35(6), 512-559.

von Hippel, W., Brener, L., \& von Hippel, C. (2008). Implicit prejudice toward injecting drug users predicts intentions to change jobs among drug and alcohol nurses. Psychological Science, 19(1), 7 -11.

Hofmann, W., De Houwer, J., Perugini, M., Baeyens, F., \& Crombez, G. (2010). Evaluative conditioning in humans: a meta-analysis. Psychological Bulletin, 136(3), 390-421.

Hofmann, W., Gawronski, B., Gschwendner, T., Le, H., \& Schmitt, M. (2005). A meta-analysis on the correlation between the Implicit Association Test and explicit self-report measures. Personality and Social Psychology Bulletin, 31(10), 1369-1385.

Hofmann, W., Gschwendner, T., Castelli, L., \& Schmitt, M. (2008). Implicit and explicit attitudes and interracial interaction: The moderating role of situationally available control resources. Group Processes \& Intergroup Relations, 11(1), 69 -87.

Hofmann, W., Gschwendner, T., Nosek, B.A., \& Schmitt, M. (2005). What moderates implicitexplicit consistency? European Review of Social Psychology, 16(1), 335-390.

Hugenberg, K., \& Bodenhausen, G.V. (2003). Facing prejudice: Implicit prejudice and the perception of facial threat. Psychological Science, , 14(6), 640-643.

Huguet, P., Croizet, J., \& Richetin, J. (2004). Is "what has been cared for" necessarily good? Further evidence for the negative impact of cosmetics use on impression formation. Journal of Applied Social Psychology, 34(8), 1752-1771.

Jost, J.T., Banaji, M.R., \& Nosek, B.A. (2004). A decade of system justification theory: Accumulated evidence of conscious and unconscious bolstering of the status quo. Political Psychology, 25(6), 881-919.

Jost, J.T., Pelham, B.W., \& Carvallo, M.R. (2002). Non-conscious forms of system justification: Cognitive, affective, and behavioral preferences for higher status groups. Journal of Experimental Social Psychology, 38(6), 586.

Jost, J.T., Rudman, L.A., Blair, I.V., Carney, D.R., Dasgupta, N., Glaser, J., \& Hardin, C.D. (2009). The existence of implicit bias is beyond reasonable doubt: A refutation of ideological and methodological objections and executive summary of ten studies that no manager should ignore. Research in Organizational Behavior, 29, 39-69.

Joy-Gaba, J.A., \& Nosek, B.A. (2010). The surprisingly limited malleability of implicit racial evaluations. Social Psychology, 41(3), 137-146.

Judd, C.M., \& Kulik, J.A. (1980). Schematic effects of social attitudes on information processing and recall. Journal of Personality and Social Psychology, 38(4), 569-578.

Karpinski, A., \& Hilton, J.L. (2001). Attitudes and the Implicit Association Test. Journal of Personality and Social Psychology, 81, 774-788.

Karpinski, A., Steinberg, J.A., Versek, B., \& Alloy, L.B. (2007). The Breadth-Based Adjective Rating Task (BART) as an indirect measure of self-esteem. Social Cognition, 25(6), 778818.

Karpinski, A., \& Steinman, R.B. (2006). The Single Category Implicit Association Test as a measure of implicit social cognition. Journal of Personality and Social Psychology, 91(1), 16-32.

Karpinski, A., Steinman, R.B., \& Hilton, J.L. (2005). Attitude importance as a moderator of the relationship between implicit and explicit attitude measures. Personality and Social Psychology Bulletin, 31(7), 949 -962. 
Kim, D.Y. (2003). Voluntary controllability of the Implicit Association Test (IAT). Social Psychology Quarterly, 83-96.

Klauer, K.C., \& Teige-Mocigemba, S. (2007). Controllability and resource dependence in automatic evaluation. Journal of Experimental Social Psychology, 43(4), 648-655.

Klein, A.M., Becker, E.S., \& Rinck, M. (2010). Approach and avoidance tendencies in spider fearful children: The Approach-Avoidance Task. Journal of Child and Family Studies.

Knowles, E.D., Lowery, B.S., \& Schaumberg, R.L. (2010). Racial prejudice predicts opposition to Obama and his health care reform plan. Journal of Experimental Social Psychology, 46(2), 420-423.

Kocan, S.E., \& Curtis, G.J. (2009). Close encounters of the initial kind: Implicit self-esteem, name-letter similarity, and social distance. Basic \& Applied Social Psychology, 31(1), 17 23.

Koole, S.L., Dijksterhuis, A., \& van Knippenberg, A. (2001). What's in a name: Implicit selfesteem and the automatic self. Journal of Personality and Social Psychology, 80(4), 669685.

Lane, K. A., Kang, J., \& Banaji, M. R. (2007). Implicit social cognition and law. Annual Review of Law and Social Science, 3, 427-451.

Lane, K.A., Banaji, M.R., Nosek, B.A., \& Greenwald, A.G. (2007). Understanding and using the Implicit Association Test: IV: What we know (so far) about the method. In B. Wittenbrink \& N. Schwarz (Eds.), Implicit measures of attitudes (pp. 59-102). New York: Guilford Press.

Lange, W., Keijsers, G., Becker, E.S., \& Rinck, M. (2008). Social anxiety and evaluation of social crowds: Explicit and implicit measures. Behaviour Research and Therapy, 46(8), 932-943.

Lee, S., Rogge, R.D., \& Reis, H.T. (2010). Assessing the seeds of relationship decay. Psychological Science, 21(6), 857 -864.

Lindner, N.M., \& Nosek, B.A. (2009). Alienable speech: Ideological variations in the application of free-speech principles. Political Psychology, 30(1), 67-92.

Livingston, R.W., \& Brewer, M.B. (2002). What are we really priming? Cue-based versus category-based processing of facial stimuli. Journal of Personality and Social Psychology, 82(1), 5-18.

Maass, A., Salvi, D., Arcuri, L., \& Semin, G. (1989). Language use in intergroup contexts: The Linguistic Intergroup Bias. Journal of Personality and Social Psychology, 57(6), 981993.

Marquardt, N., \& Hoeger, R. (2008). The effect of implicit moral attitudes on managerial decision-making: An implicit social cognition approach. Journal of Business Ethics, 85(2), 157-171.

McConahay, J.B. (1983). Modern racism and modern discrimination. Personality and Social Psychology Bulletin, 9(4), 551 -558.

McConnell, A.R., \& Leibold, J.M. (2001). Relations among the Implicit Association Test, discriminatory behavior, and explicit measures of racial attitudes. Journal of Experimental Social Psychology, 37(5), 435-442.

Mendes, W.B., Gray, H.M., Mendoza-Denton, R., Major, B., \& Epel, E.S. (2007). Why egalitarianism might be good for your health. Psychological Science, 18(11), 991-998.

Mierke, J., \& Klauer, K.C. (2003). Method-specific variance in the Implicit Association Test. Journal of Personality and Social Psychology, 85(6), 1180-1192. 
Mitchell, C.J., Anderson, N.E., \& Lovibond, P.F. (2003). Measuring evaluative conditioning using the Implicit Association Test. Learning and Motivation, 34(2), 203-217.

Mitchell, J.P., Nosek, B.A., \& Banaji, M.R. (2003). Contextual variations in implicit evaluation. Journal of Experimental Psychology: General, 132(3), 455-469.

Mogg, K., Bradley, B.P., Field, M., \& De Houwer, J. (2003). Eye movements to smoking-related pictures in smokers: relationship between attentional biases and implicit and explicit measures of stimulus valence. Addiction, 98(6), 825-836.

Molesworth, B.R.C., \& Chang, B. (2009). Predicting pilots' risk-taking behavior through an Implicit Association Test. Human Factors, , 51(6), 845 -857.

Nisbett, R.E., \& Wilson, T.D. (1977). The halo effect: Evidence for unconscious alteration of judgments. Journal of Personality and Social Psychology, 35(4), 250-256.

Nock, M.K., Park, J.M., Finn, C.T., Deliberto, T.L., Dour, H.J., \& Banaji, M.R. (2010). Measuring the suicidal mind. Psychological Science, 21(4), 511 -517.

Nosek, B.A. (2005). Moderators of the relationship between implicit and explicit evaluation. Journal of Experimental Psychology: General, 134(4), 565-584.

Nosek, B.A. (2007). Understanding the individual implicitly and explicitly. International Journal of Psychology, 42(3), 184-188.

Nosek, B.A., \& Banaji, M.R. (2005). The Go/No-Go Association Task. Social Cognition, 19(6), 625-666.

Nosek, B.A., Banaji, M.R., \& Greenwald, A.G. (2002). Math = male, me = female, therefore math $\neq$ me. Journal of Personality and Social Psychology, 83(1), 44-59.

Nosek, B.A., Graham, J., \& Hawkins, C. (2010). Implicit political cognition. In B. Gawronski \& B.K. Payne (Eds.), Handbook of Implicit Social Cognition: Measurement, Theory, and Applications. New York, NY: Guilford Press.

Nosek, B.A., \& Greenwald, A.G. (2009). (Part of) the case for a pragmatic approach to validity: Comment on De Houwer, Teige-Mocigemba, Spruyt, and Moors (2009). Psychological Bulletin, 135(3), 373-376.

Nosek, B.A., Greenwald, A.G., \& Banaji, M.R. (2005). Understanding and using the Implicit Association Test: II. Method variables and construct validity. Personality and Social Psychology Bulletin, 31(2), $166-180$.

Nosek, B.A., Greenwald, A.G., \& Banaji, M.R. (2007). The Implicit Association Test at age 7: A methodological and conceptual review. In J.A. Bargh (Ed.), Social psychology and the unconscious: The automaticity of higher mental processes (pp. 265-292). New York: Psychology Press.

Nosek, B.A., \& Hansen, J.J. (2008). Personalizing the Implicit Association Test increases explicit evaluation of target concepts. European Journal of Psychological Assessment, 24(4), 226-236.

Nosek, B.A., Hawkins, C.B., \& Frazier, R.S. (2011). Implicit social cognition: From measures to mechanisms. Trends in Cognitive Sciences.

Nosek, B.A., \& Smyth, F.L. (2007). A multitrait-multimethod validation of the Implicit Association Test: Implicit and explicit attitudes are related but distinct constructs. Experimental Psychology, 54(1), 14-29.

Nosek, B.A., \& Smyth, F.L. (in press). Implicit social cognitions predict sex differences in math engagement and achievement. American Educational Research Journal.

Nosek, B.A., Smyth, F.L., Sriram, N., Lindner, N.M., Devos, T., Ayala, A., Bar-Anan, Y., et al. (2009). National differences in gender-science stereotypes predict national sex 
differences in science and math achievement. Proceedings of the National Academy of Sciences, 106(26), 10593 -10597.

Nosek, B.A., \& Sriram, N. (2007). Faulty assumptions: A comment on Blanton, Jaccard, Gonzales, and Christie (2006). Journal of Experimental Social Psychology, 43, 393-398.

Nuttin, J.M. (1985). Narcissism beyond Gestalt and awareness: The name letter effect. European Journal of Social Psychology, 15, 353-361.

Olson, K.R., \& Dunham, Y. (2010). The development of implicit social cognition. In B. Gawronski \& B.K. Payne (Eds.), Handbook of Implicit Social Cognition: Measurement, Theory, and Applications. New York, NY: Guilford Press.

Olson, M.A., \& Fazio, R.H. (2003). Relations between implicit measures of prejudice. Psychological Science, 14(6), 636 -639.

Olson, M.A., \& Fazio, R.H. (2004). Reducing the influence of extrapersonal associations on the Implicit Association Test: Personalizing the IAT. Journal of Personality and Social Psychology, 86(5), 653-667.

Otten, S., \& Wentura, D. (1999). About the impact of automaticity in the minimal group paradigm: evidence from affective priming tasks. European Journal of Social Psychology, 29(8), 1049-1071.

Page-Gould, E., Mendoza-Denton, R., \& Tropp, L.R. (2008). With a little help from my crossgroup friend: Reducing anxiety in intergroup contexts through cross-group friendship. Journal of Personality and Social Psychology, 95(5), 1080-1094.

Paladino, M., \& Castelli, L. (2008). On the immediate consequences of intergroup categorization: Activation of approach and avoidance motor behavior toward ingroup and outgroup members. Personality and Social Psychology Bulletin, 34(6), 755 -768.

Payne, B.K., Burkley, M.A., \& Stokes, M.B. (2008). Why do implicit and explicit attitude tests diverge? The role of structural fit. Journal of Personality and Social Psychology, 94(1), 16-31.

Payne, B.K., Cheng, C.M., Govorun, O., \& Stewart, B.D. (2005). An inkblot for attitudes: Affect misattribution as implicit measurement. Journal of Personality and Social Psychology, 89(3), 277-293.

Payne, B.K., Krosnick, J.A., Pasek, J., Lelkes, Y., Akhtar, O., \& Tompson, T. (2010). Implicit and explicit prejudice in the 2008 American presidential election. Journal of Experimental Social Psychology, 46(2), 367-374.

Payne, B.K., McClernon, F.J., \& Dobbins, I.G. (2007). Automatic affective responses to smoking cues. Experimental and Clinical Psychopharmacology, 15(4), 400-409.

Penner, L.A., Dovidio, J.F., West, T.V., Gaertner, S.L., Albrecht, T.L., Dailey, R.K., \& Markova, T. (2010). Aversive racism and medical interactions with Black patients: A field study. Journal of Experimental Social Psychology, 46(2), 436-440.

Pérez, E.O. (in press). Explicit evidence on the import of implicit attitudes: The IAT and immigration policy judgments. Political Behavior.

Perkins, A., \& Forehand, M. (2010). Implicit social cognition and indirect measures in consumer behavior. In B. Gawronski \& B.K. Payne (Eds.), Handbook of Implicit Social Cognition. New York, NY: Guilford Press.

Perugini, M., Richetin, J., \& Zogmaister, C. (2010) Prediction of behavior. In B. Gawronski and B.K. Payne (Eds.), Handbook of Implicit Social Cognition (pp. 255-277) New York, NY: Guilford. 
Phelps, E.A., O'Connor, K.J., Cunningham, W.A., Funayama, E.S., Gatenby, J.C., Gore, J.C., \& Banaji, M.R. (2000). Performance on indirect measures of race evaluation predicts amygdala activation. Journal of Cognitive Neuroscience, 12(5), 729-738.

Pinter, B., \& Greenwald, A.G. (2004). Exploring implicit partisanship: Enigmatic (but genuine) group identification and attraction. Group Processes \& Intergroup Relations, 7(3), 283 296.

Plant, E.A., Devine, P.G., Cox, W.T., Columb, C., Miller, S.L., Goplen, J., \& Peruche, B.M. (2009). The Obama effect: Decreasing implicit prejudice and stereotyping. Journal of Experimental Social Psychology, 45(4), 961-964.

Polaschek, D.L.L., Bell, R.K., Calvert, S.W., \& Takarangi, M.K.T. (2010). Cognitivebehavioural rehabilitation of high-risk violent offenders: Investigating treatment change with explicit and implicit measures of cognition. Applied Cognitive Psychology, 24(3), 437-449.

Prestwich, A., Perugini, M., Hurling, R., \& Richetin, J. (2010). Using the self to change implicit attitudes. European Journal of Social Psychology, 40(1), 61-71.

Quadflieg, S., Turk, D.J., Waiter, G.D., Mitchell, J.P., Jenkins, A.C., \& Macrae, C.N. (2009). Exploring the neural correlates of social stereotyping. Journal of Cognitive Neuroscience, 21(8), 1560-1570.

Radvansky, G.A., Copeland, D.E., \& Hippel, W.V. (2010). Stereotype activation, inhibition, and aging. Journal of Experimental Social Psychology, 46(1), 51-60.

Ranganath, K.A., \& Nosek, B.A. (2008). Implicit attitude generalization occurs immediately; explicit attitude generalization takes time. Psychological Science, 19(3), 249-254.

Ranganath, K.A., Smith, C.T., \& Nosek, B.A. (2008). Distinguishing automatic and controlled components of attitudes from direct and indirect measurement methods. Journal of Experimental Social Psychology, 44(2), 386-396.

Richeson, J.A., Baird, A.A., Gordon, H.L., Heatherton, T.F., Wyland, C.L., Trawalter, S., \& Shelton, J.N. (2003). An fMRI investigation of the impact of interracial contact on executive function. Nature Neuroscience, 6(12), 1323-1328.

Roccato, M., \& Zogmaister, C. (2010). Predicting the vote through implicit and explicit attitudes: A field research. Political Psychology, 31(2), 249-274.

Roediger, H.L. (1990). Implicit memory: Retention without remembering. American Psychologist, 45(9), 1043-1056.

Rooth, D. (2010). Automatic associations and discrimination in hiring: Real world evidence. Labour Economics, 17(3), 523-534.

Rothermund, K., Teige-Mocigemba, S., Gast, A., \& Wentura, D. (2009). Minimizing the influence of recoding in the Implicit Association Test: The Recoding-Free Implicit Association Test (IAT-RF). Quarterly Journal of Experimental Psychology, 62(1), 84-98.

Rudman, L.A., Ashmore, R.D., \& Gary, M.L. (2001). "Unlearning" automatic biases: the malleability of implicit prejudice and stereotypes. Journal of Personality and Social Psychology, 81(5), 856-868.

Rudman, L.A., Dohn, M.C., \& Fairchild, K. (2007). Implicit self-esteem compensation: automatic threat defense. Journal of Personality and Social Psychology, 93(5), 798-813.

Rudolph, A., Schröder-Abé, M., Riketta, M., \& Schütz, A. (2010). Easier when done than said! Implicit self-esteem predicts observed or spontaneous behavior, but not self-reported or controlled behavior. Zeitschrift für Psychologie,, 218(1), 12-19. 
Rüsch, N., Corrigan, P.W., Todd, A.R., \& Bodenhausen, G.V. (2010). Implicit self-stigma in people with mental illness. The Journal of Nervous and Mental Disease, 198(2), 150-153.

Salthouse, T.A. (2010). Major issues in cognitive aging. New York, NY: Oxford University Press.

Sassenberg, K., \& Wieber, F. (2005). Don't ignore the other half: The impact of ingroup identification on implicit measures of prejudice. European Journal of Social Psychology, 35(5), 621-632.

Schmidt, K., \& Nosek, B.A. (2010). Implicit (and explicit) racial attitudes barely changed during Barack Obama's presidential campaign and early presidency. Journal of Experimental Social Psychology, 46(2), 308-314.

Schnabel, K., Banse, R., \& Asendorpf, J. (2006). Employing automatic approach and avoidance tendencies for the assessment of implicit personality self-concept. Experimental Psychology, 53(1), 69-76.

Schneider, W., \& Shiffrin, R.M. (1977). Controlled and automatic human information processing: 1. Detection, search, and attention. Psychological Review, 84(1), 1-66.

Sekaquaptewa, D., Espinoza, P., Thompson, M., Vargas, P., \& von Hippel, W. (2003). Stereotypic explanatory bias: Implicit stereotyping as a predictor of discrimination.

Semin, G., \& Fiedler, K. (1991). The linguistic category model, its bases, applications and range. In W. Stroebe \& M. Hewstone (Eds.), European review of social psychology (Vol. 2, pp.1-30). Chichester, England: Wiley.

Sherman, S.J., Chassin, L., Presson, C., Seo, D., \& Macy, J.T. (2009). The intergenerational transmission of implicit and explicit attitudes toward smoking: Predicting adolescent smoking initiation. Journal of Experimental Social Psychology, 45(2), 313-319.

Sherman, S.J., Rose, J.S., Koch, K., Presson, C.C., \& Chassin, L. (2003). Implicit and explicit attitudes toward cigarette smoking: The effects of context and motivation. Journal of Social and Clinical Psychology, 22(1), 13-39.

Shook, N.J., \& Fazio, R.H. (2008). Interracial roommate relationships: An experimental field test of the contact hypothesis. Psychological Science, 19(7), 717-723.

Sinclair, S., Lowery, B.S., Hardin, C.D., \& Colangelo, A. (2005). Social tuning of automatic racial attitudes: The role of affiliative motivation. Journal of Personality and Social Psychology, 89(4), 583-592.

Smith, E.R., \& DeCoster, J. (2000). Dual-process models in social and cognitive psychology: Conceptual integration and links to underlying memory systems. Personality and Social Psychology Review, 4(2), 108 -131.

Snowden, R.J., \& Gray, N.S. (2010). Implicit social cognition in forensic settings. In B. Gawronski \& B. K. Payne (Eds.), Handbook of Implicit Social Cognition. New York, NY: Guilford Press.

Snowden, R.J., Wichter, J., \& Gray, N.S. (2007). Implicit and explicit measurements of sexual preference in gay and heterosexual men: A comparison of priming techniques and the Implicit Association Task. Archives of Sexual Behavior, 37(4), 558-565.

Spalding, L.R., \& Hardin, C.D. (1999). Unconscious unease and self-handicapping: Behavioral consequences of individual differences in implicit and explicit self-esteem. Psychological Science, 10(6), 535 -539.

Sriram, N., \& Greenwald, A.G. (2009). The brief implicit association test. Experimental Psychology, 56(4), 283-294. 
Sriram, N., Greenwald, A.G., \& Nosek, B.A. (2010). Correlational biases in mean response latency differences. Statistical Methodology, 7(3), 277-291.

Srivastava, S., \& Banaji, M.R. (in press). Behind the front: Collaborative networks and implicit cognition in organizations. American Sociological Review.

Steffens, M.C. (2004). Is the implicit association test immune to faking? Experimental Psychology, 51(3), 165-179.

Stout, J. G., Dasgupta, N., Hunsinger, M., \& McManus, M. (in press). STEMing the tide: Using ingroup experts to inoculate women's self-concept and professional goals in science, technology, engineering, and mathematics (STEM). Journal of Personality and Social Psychology.

Strack, F., \& Deutsch, R. (2004). Reflective and impulsive determinants of social behavior. Personality and Social Psychology Review,8(3), 220-247.

Swanson, J.E., Rudman, L.A., \& Greenwald, A.G. (2001). Using the Implicit Association Test to investigate attitude-behavior consistency for stigmatized behavior. Cognition and Emotion, 15(2), 207-230.

Tajfel, H., \& Turner, J.C. (1986). The social identity theory of intergroup behavior. In S. Worchel \& W. G. Austin (Eds.), In Psychology of intergroup relations (pp. 7-24). Chicago, IL: Nelson-Hall Publishers.

Teachman, B.A., Cody, M., \& Clerkin, E. (2010). Clincial applications of implicit measures. In B. Gawronski \& B.K. Payne (Eds.), Handbook of Implicit Social Cognition.. New York, NY: Guilford Press.

Teachman, B.A., Gregg, A.P., \& Woody, S.R. (2001). Implicit associations for fear-relevant stimuli among individuals with snake and spider fears. Journal of Abnormal Psychology, $110(2), 226-235$.

Teachman, B.A., Smith-Janik, S.B., \& Saporito, J. (2007). Information processing biases and panic disorder: Relationships among cognitive and symptom measures. Behaviour research and therapy, 45(8), 1791-1811.

Teachman, B.A., \& Woody, S.R. (2003). Automatic processing in spider phobia: Implicit fear associations over the course of treatment. Journal of Abnormal Psychology, 112(1), 100109.

Teige-Mocigemba, S., Klauer, K.C., \& Rothermund, K. (2008). Minimizing method-specific variance in the IAT: A single block IAT. European Journal of Psychological Assessment, 24(4), 237-245.

Teige-Mociemba, S., Klauer, K.C., \& Sherman, J.W. (2010). A practical guide to Implicit Association Tests and related tasks. In B. Gawronski and B. K. Payne (Eds.), Handbook of Implicit Social Cognition (pp. 117-139) New York, NY: Guilford.

Tetlock, P., \& Mitchell, G. (2009). Implicit bias and accountability systems: What must organizations do to prevent discrimination? In B. Staw \& A. Brief (Eds.), Research in organizational behavior (Vol. 29, pp. 71-72). New York, NY: Elsevier.

Teubel, T., Asendorpf, J.B., Banse, R., \& Schnabel, K. (in press). Implicit but not explicit aggressiveness predicts performance outcome in basketball players. International Journal of Sport Psychology.

Thush, C., Wiers, R.W., Ames, S.L., Grenard, J.L., Sussman, S., \& Stacy, A.W. (2008). Interactions between implicit and explicit cognition and working memory capacity in the prediction of alcohol use in at-risk adolescents. Drug and Alcohol Dependence, 94(1-3), 116-124. 
van Leeuwen, M.L., Veling, H., van Baaren, R.B., \& Dijksterhuis, A. (2009). The influence of facial attractiveness on imitation. Journal of Experimental Social Psychology, 45(6), 1295-1298.

Walther, E. (2002). Guilty by mere association: evaluative conditioning and the spreading attitude effect. Journal of Personality and Social Psychology, 82(6), 919-934.

Weigel, R.H., \& Howes, P.W. (1985). Conceptions of racial prejudice: Symbolic racism reconsidered. Journal of Social Issues, 41(3), 117-38.

Wentura, D. \& Degner, J. (2010) A practical guide to sequential priming and related tasks. In B. Gawronski and B.K. Payne (Eds.), Handbook of Implicit Social Cognition (pp. 95-116) New York, NY: Guilford.

Whitfield, M., \& Jordan, C.H. (2009). Mutual influence of implicit and explicit attitudes. Journal of Experimental Social Psychology, 45(4), 748-759.

Wiers, R.W., Houben, K., Roefs, A., de Jong, P.J., Hofmann, W., \& Stacy, A.W. (2010). Implicit cognition in health psychology: Why common sense goes out the window. In B. Gawronski \& B.K. Payne (Eds.), Handbook of Implicit Social Cognition. New York, NY: Guilford Press.

Wiers, R.W., Rinck, M., Kordts, R., Houben, K., \& Strack, F. (2010). Retraining automatic action-tendencies to approach alcohol in hazardous drinkers. Addiction, 105, 279-287.

Wilson, T.D., Lindsey, S., \& Schooler, T.Y. (2000). A model of dual attitudes. Psychological Review, 107(1), 101-126.

Wittenbrink, B., Judd, C.M., \& Park, B. (1997). Evidence for racial prejudice at the implicit level and its relationship with questionnaire measures. Journal of Personality and Social Psychology, 72(2), 262-274.

Wittenbrink, B., Judd, C.M., \& Park, B. (2001). Spontaneous prejudice in context: Variability in automatically activated attitudes. Journal of Personality and Social Psychology, 81(5), 815-827. 